OPEN ACCESS

Edited by:

Patrick Joseph Moynihan, University of Birmingham,

United Kingdom

Reviewed by:

Christopher Davies,

Medical University of South Carolina,

United States

Johann Peltier,

Institut Pasteur, France

Sheena McGowan,

Monash University, Australia

*Correspondence:

Mickaël Desvaux

mickael.desvaux@inra.fr.

Specialty section:

This article was submitted to Microbial Physiology and Metabolism,

a section of the journal

Frontiers in Microbiology

Received: 09 August 2018 Accepted: 08 February 2019 Published: 28 February 2019

Citation:

Vermassen A, Leroy S, Talon $R$

Provot $C$, Popowska $M$ and

Desvaux M (2019) Cell Wall

Hydrolases in Bacteria: Insight on the

Diversity of Cell Wall Amidases,

Glycosidases and Peptidases Toward

Peptidoglycan.

Front. Microbiol. 10:331.

doi: 10.3389/fmicb.2019.00331

\section{Cell Wall Hydrolases in Bacteria: Insight on the Diversity of Cell Wall Amidases, Glycosidases and Peptidases Toward Peptidoglycan}

\author{
Aurore Vermassen ${ }^{1}$, Sabine Leroy ${ }^{1}$, Régine Talon ${ }^{1}$, Christian Provot ${ }^{2}$, \\ Magdalena Popowska ${ }^{3}$ and Mickaël Desvaux ${ }^{1 *}$ \\ ${ }^{1}$ Université Clermont Auvergne, INRA, MEDiS, Clermont-Ferrand, France, ${ }^{2}$ BioFilm Control SAS, Saint-Beauzire, France, \\ ${ }^{3}$ Department of Applied Microbiology, Faculty of Biology, Institute of Microbiology, University of Warsaw, Warsaw, Poland
}

The cell wall (CW) of bacteria is an intricate arrangement of macromolecules, at least constituted of peptidoglycan (PG) but also of (lipo)teichoic acids, various polysaccharides, polyglutamate and/or proteins. During bacterial growth and division, there is a constant balance between CW degradation and biosynthesis. The $\mathrm{CW}$ is remodeled by bacterial hydrolases, whose activities are carefully regulated to maintain cell integrity or lead to bacterial death. Each cell wall hydrolase $(\mathrm{CWH})$ has a specific role regarding the PG: (i) cell wall amidase (CWA) cleaves the amide bond between $\mathrm{N}$-acetylmuramic acid and $\mathrm{L}$-alanine residue at the $\mathrm{N}$-terminal of the stem peptide, (ii) cell wall glycosidase (CWG) catalyses the hydrolysis of the glycosidic linkages, whereas (iii) cell wall peptidase (CWP) cleaves amide bonds between amino acids within the PG chain. After an exhaustive overview of all known conserved catalytic domains responsible for CWA, CWG, and CWP activities, this review stresses that the CWHs frequently display a modular architecture combining multiple and/or different catalytic domains, including some lytic transglycosylases as well as CW binding domains. From there, direct physiological and collateral roles of CWHs in bacterial cells are further discussed.

Keywords: bacterial cell wall, peptidoglycan (PG) hydrolases, protein modules, cell wall binding domains, bacterial division and growth, cell lysis, cell wall remodeling

\section{INTRODUCTION}

The first bacterial cell wall hydrolase (CWH) was discovered in 1921 by the Scottish bacteriologist Sir Alexander Fleming, who is well known for his 1928 discovery of the antibiotic penicillin (Fleming, 1929). He had observed "a remarkable bacteriolytic element," which caused bacterial lysis on an agar plate and which he called "lysozyme" in 1922. Lysozyme cleaves the $\beta$-(1-4)-glycosidic bond between $\mathrm{N}$-acetylmuramic acid (MurNAc) and $\mathrm{N}$-acetylglucosamine (GlcNAc) in peptidoglycan (PG) (Chipman et al., 1967). This hydrolytic enzyme has served as a model in protein biochemistry and its contribution to antibacterial defense is well recognized.

The bacterial cell wall (CW) is a complex arrangement of macromolecules that varies depending on the species of bacteria and whether they are parietal monoderm bacteria (archetypal Gram-positive bacteria), lipopolysaccharidic diderm bacteria (archetypal Gram-negative bacteria) or mycolate diderm bacteria (archetypal acid-fast bacteria) 
(Desvaux et al., 2018; Figure 1). While the PG is the major polymer of the CW, teichoic and lipoteichoic acids as well as other macromolecular components like polysaccharides, polyglutamate or proteins can also be (Neuhaus and Baddiley, 2003; Dramsi et al., 2008; Vollmer et al., 2008a). In resisting to internal turgor pressure to maintain bacterial cell integrity and shape, the $\mathrm{CW}$ is essential to bacterial growth under various environmental conditions (Weidel and Pelzer, 1964; Vollmer et al., 2008a). Besides, it needs to be remodeled to accommodate cell elongation and division for proper bacterial growth. In $\mathrm{CW}$-monoderm bacteria, the $\mathrm{CW}$ is an interface between the cell and its environment and participates in interactions with abiotic surfaces, bacteriophages and eukaryotic host cells (Silhavy et al., 2010).

Depending on the CW bonds they specifically cleave, CWHs can be discriminated into three types of enzymes, namely amidases, glycosidases or peptidases (Rigden et al., 2003; Fenton et al., 2010; Szweda et al., 2012). CWHs were historically described as lysins and classified as endolysins, exolysins and/or autolysins based on their origin and role (Vollmer et al., 2008b; Schmelcher et al., 2012). In fact, endolysins referred to bacteriophage encoded CWHs degrading the CW of the host bacterium upon activation of the lytic cycle. Exolysins referred to secreted bacterial CWHs aiming at killing bacterial cells of different species or even strains within the same species. Rather than bacterial cell lysis, autolysins referred to hydrolases mainly involved in CW remodeling in the course of bacterial cell division (Vollmer et al., 2008b; Vollmer, 2012). However, advances in biochemical and structural characterization indicate that these lysins include amidases, glycosidases and peptidases. In function, endolysins are similar to exolysins and autolysins, except that these two latter hydrolases are not encoded by bacteriophages (Schmelcher et al., 2012). Moreover, a so-called autolysin can induce cell lysis (and not just CW remodeling) when its expression is not tightly controlled (Typas et al., 2012). For these reasons, in this manuscript, we will favor the term CWHs over lysins, and describe them with respect to their catalytic activity into $\mathrm{CW}$ amidases, CW glycosidases and/or CW peptidases rather than endolysins, exolysins and autolysins. This nomenclature highlights the importance of the modular architecture of the polypeptide for its function. Since the PG is the only CW component targeted by CWHs characterized to date, they can be interchangeably called PG hydrolases (PGHs).

After a brief reminding of the CW structure and organization in bacteria, the different conserved domains related to bacterial CWHs are here exhaustively overviewed in order to further stress the diversity of their modular architecture and their physiological relevance is further discussed.

\section{THE CELL WALL: COMPOSITION, STRUCTURE AND ORGANIZATION}

Bacteria have developed a complex cell envelope, which helps them to survive in various environments (Vollmer et al., 2008a;
Silhavy et al., 2010). The CW is a macromolecule with an elastic-plastic behavior that defines the shape of the bacterium (Amir et al., 2014). It enables the bacterial cell to resist lysis as a result of its high intracellular osmotic pressure. In CWmonoderm bacteria, the cytoplasmic membrane is surrounded by a thick CW (10-20 layers thick) composed of PG, to which secondary polymers are covalently attached (e.g., teichoic acids (Figure 1; Vollmer et al., 2008a); in addition, lipoteichoic acids are anchored to the cytoplasmic membrane via their diacylglycerol moiety. Some polysaccharides, namely teichuronic acids or polyglutamate, and surface proteins can be covalently or non-covalently linked to the PG. Actually, the totality of the molecular components found at the bacterial cell surface refers to the surfaceome and its protein subset constitutes the proteosurfaceome (Desvaux et al., 2018). When displayed at the surface of $\mathrm{CW}$-monoderm bacteria, proteins can either be associated with the cytoplasmic membrane, i.e., IMPs (integral membrane proteins) or lipoproteins, or with the CW (Popowska and Markiewicz, 2004; Desvaux et al., 2006). At the CW, proteins can either be covalently anchored (LPXTG-proteins) or specifically associated with some CW components through weak interactions thanks to the presence of conserved motifs, e.g., LysM (lysin motif), CWB1 (CW binding repeat of type 1) or PGB1 (peptidoglycan binding domain of type 1) (Desvaux et al., 2006, 2018). In the cell envelope of LPS-diderm bacteria, the $\mathrm{CW}$ is located between the cytoplasmic membrane (then also called inner membrane) and the outer membrane, i.e., within the periplasmic space. It consists of a thin layer of PG (only 13 layers thick) linked to some lipoproteins anchored to the outer membrane (Figure 1; Torti and Park, 1976).

The molecular organization, variations in the primary structure and description of the different types of the PG in bacteria has been extensively described in dedicated reviews readily available for in-depth details (Schleifer and Kandler, 1972; Turner et al., 2014; Desvaux et al., 2018). In CWmonoderm bacteria, the PG polymer results from the crosslinking of glycan strands through peptide stems. While peptide stems originate from the lactyl moiety of the MurNAc saccharide, the glycan strands are composed of alternating MurNAc and GlcNAc saccharides (Figure 2; Bourhis and Werts, 2007; Johnson et al., 2013). In the stem peptide, the first two residues of are generally L-Ala and D-Gln or iGln, whereas D-Ala is typically the last one (Humann and Lenz, 2009). In many rod-shaped CW-monoderm bacteria, e.g., Listeria or Bacillus, a meso-diaminopimelate (mDAP) constitutes the third residue of the stem peptide. In cocci species, though, a lysine residue is found at this position (Vollmer et al., 2008a). The Staphylococcus aureus PG comprises 20 or more layers of linear glycan chains with alternating MurNAc and GlcNAc, and a L-Ala-D-iGln-L-Lys-D-Ala stem peptide (Dmitriev et al., 2004). To connect PG chains, a pentaglycine interpeptide branches off the amino group of the L-Lys of the stem peptide to the D-Ala in the position of a neighboring chain (Figure 2). In S. aureus, the PG chains have a maximum length of 23-26 disaccharide units but the majority of chains ranges between 3 and 10 (Boneca et al., 2000). Actually, most of the diversity in the PG composition 

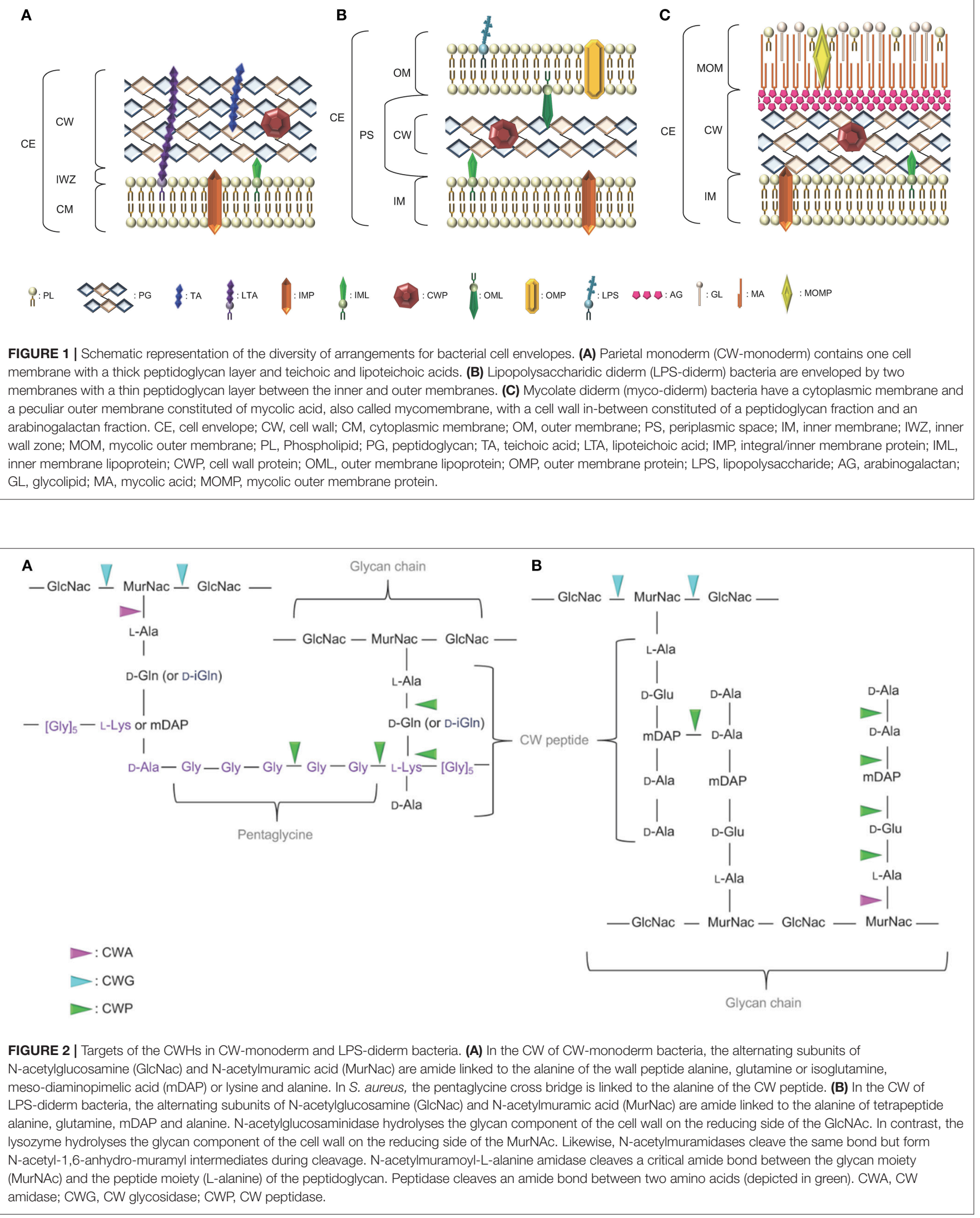
occurs with the nature of the crosslinking of the stem peptides (Schleifer and Kandler, 1972).

In LPS-diderm bacteria, the composition of PG is quite similar with alternating MurNAc and GlcNAc (Figure 2). However, a 1,6-anhydro modification is present at the end of the strand in MurNAc residue (Vollmer and Holtje, 2004). Of note, such modification can also be detected in some CW-monoderm bacteria, like B. subtilis (Atrih et al., 1999). The L-Ala-D-GlumDAP-D-Ala-D-Ala stem peptides is linked to the lactyl group of MurNAc (Figure 2). Most cross-links result from the mDAP at position 3 of one stem peptide with the D-Ala at position 4 of a second stem peptide of a neighboring glycan strand (Vollmer and Holtje, 2004). In Escherichia coli, the length of glycan chains is around 25-35 disaccharide units in average but the length distribution is quite broad (Harz et al., 1990).

In myco-diderm bacteria, the mycolic outer membrane (MOM) or mycomembrane has been intensively investigated (Niederweis et al., 2010; Jackson, 2014) and the CW located between the MOM and the IM is constituted of two main fractions, the PG and arabinogalactan (AG), which are covalently attached (Alderwick et al., 2015). The AG is actually connected to mycolic acids at the MOM then forming the so-called mycolylarabinogalactan-peptidoglycan complex. Regarding the PG and compared to CW-monoderm or LPS-diderm bacteria, much less information is available but it is generally assumed its synthesis is similar to that of E. coli (Schleifer and Kandler, 1972; Van Heijenoort, 2001; Alderwick et al., 2015). Briefly, the PG in myco-diderm bacteria is composed of alternating GlcNAc and MurNAc, linked in a $\beta-1,4$ configuration (Alderwick et al., 2015). Besides MurNAc, N-glycolyl derivatives of the muramic acid (MurNGly) are also present as a result of the oxidation of the $\mathrm{N}$-acetyl group to a $\mathrm{N}$-glycolyl group. Regarding the stem peptides, the proportion of cross-linking is also significantly higher in myco-diderm bacteria compared to LPSdiderm bacteria as observed for Mycobacterium species vs. E. coli (Alderwick et al., 2015).

In both CW-monoderm and LPS-diderm bacteria, modifications to the basic PG structure such as $\mathrm{N}$-glycosylation, $\mathrm{O}$-acetylation and/or $\mathrm{N}$-deacetylation occur frequently and many of them are species-specific (Markiewicz and Popowska, 2011). Moreover, in response to environmental conditions, the PG structure of a given bacterium may also change. Such modifications could enhance resistance to antibiotics and host degradative enzymes targeting the CW. Modifications to the basic PG structure occur at several levels, namely in the disaccharide backbone, the bridge regions, and the peptide stem (Humann and Lenz, 2009).

\section{CELL WALL HYDROLASES IN BACTERIA}

The classification of a $\mathrm{CWH}$ as $\mathrm{CW}$ amidase, $\mathrm{CW}$ glycosidase and/or CW peptidase is associated with the presence of conserved catalytic domains respective to these different enzymatic activities (Alcorlo et al., 2017). These functionally important domains can be identified in proteins following searches against Interpro (IPR) (Mitchell et al., 2019), the most renown and reliable integrative protein signature databank regrouping different specialist member databases, such as Pfam (Finn et al., 2016), SMART (Letunic and Bork, 2018) or CDD (MarchlerBauer et al., 2017). In fact, the identification of a conserved motif based on a probabilistic match against HMM (hidden Markov model) or even PSSM (position-specific scoring matrix) profiles is more effective, relevant and robust than a percentage of identity or similarity against regular expressions (Nagl, 2003). The cleavage sites of the PG by the different CWHs are shown in Figure 2. To date, only CWHs involved in the degradation of PG have been reported, and consequently they can be synonymously and more precisely called PGHs, at least until CWHs targeting other components of the CW are reported and characterized. Regarding the structure of solved CWHs readers can refer to recent review for further in-depth knowledge (Alcorlo et al., 2017; Broendum et al., 2018).

\section{Cell Wall Amidases (CWA, E.C.3.5.1)}

CWAs actually correspond to $\mathrm{N}$-acetylmuramoyl-L-alanine amidases (NALAAs) and can also be called PG amidases (PGAs) or amidases in the scientific literature (Young, 1992; Shockman et al., 1996). They hydrolyse the amide bond separating the glycan strand from the stem peptide, that is between the MurNAc and L-alanine residues (Holtje, 1995; Vollmer et al., 2008b). In bacteria, three different types of catalytic domains are currently reported as responsible for a NALAA activity, namely (i) N-acetylmuramoyl-L-alanine amidase of type 2 (NALAA2; IPR002502), (ii) N-acetylmuramoyl-L-alanine amidase of type 3 (NALAA-3; IPR002508), and (iii) $\mathrm{N}$-acetylmuramoylL-alanine amidase of type 5 (NALAA-5; IPR008044) (Table 1 and Figure 3).

\section{$\mathrm{N}$-acetylmuramoyl-L-alanine amidase of Type 2 (NALAA-2)}

The NALAA-2 domain is about 125 amino acids long (IPR002502). E. coli AmpD is one of the most investigated CWHs with a NALAA-2 domain (Holtje et al., 1994; Van Heijenoort, 2001). This enzyme rapidly cleaves 1,6-anhydroMurNAc-L-Ala bonds in MurNAc-tri and tetrapeptides. AmiD (amidase D) has a broader substrate specificity in cleaving both 1,6-anhydro-MurNAc-L-Ala and MurNAc-L-Ala bonds (Pennartz et al., 2009). In some Bacillus species, a truncated version of this domain can be found, that is the NALAA2C (N-acetylmuramoyl-L-alanine amidase domain of type $2 \mathrm{C}$ terminal; IPR021976), which remains poorly understood (Yang et al., 2013). The structure of NALAA-2 catalytic domain has been extensively investigated (Table 1; Firczuk and Bochtler, 2007; Alcorlo et al., 2017). The catalysis is zinc-dependent and occurs in a L-shape cavity where the $\mathrm{Zn}^{2+}$ cation is located at the intersection of the region for the glycan binding and the region for the peptide stem binding (Lee et al., 2013; Martinez-Caballero et al., 2013). NALAA-2 has an open and closed conformation as the enzyme activation involves important structural rearrangements at the substrate and peptide-stem binding sites (Liepinsh et al., 2003; Carrasco-Lopez et al., 2011). 


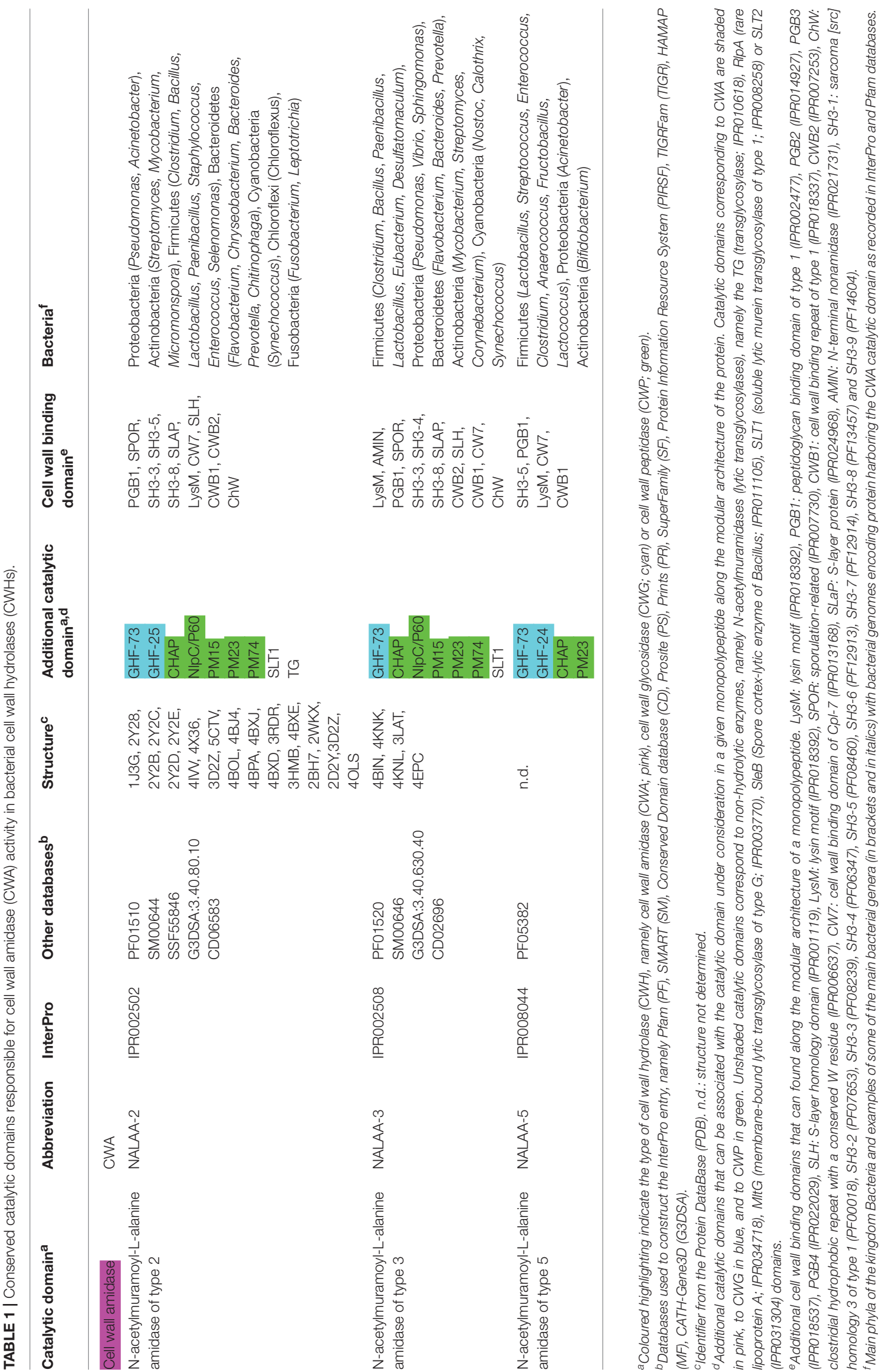




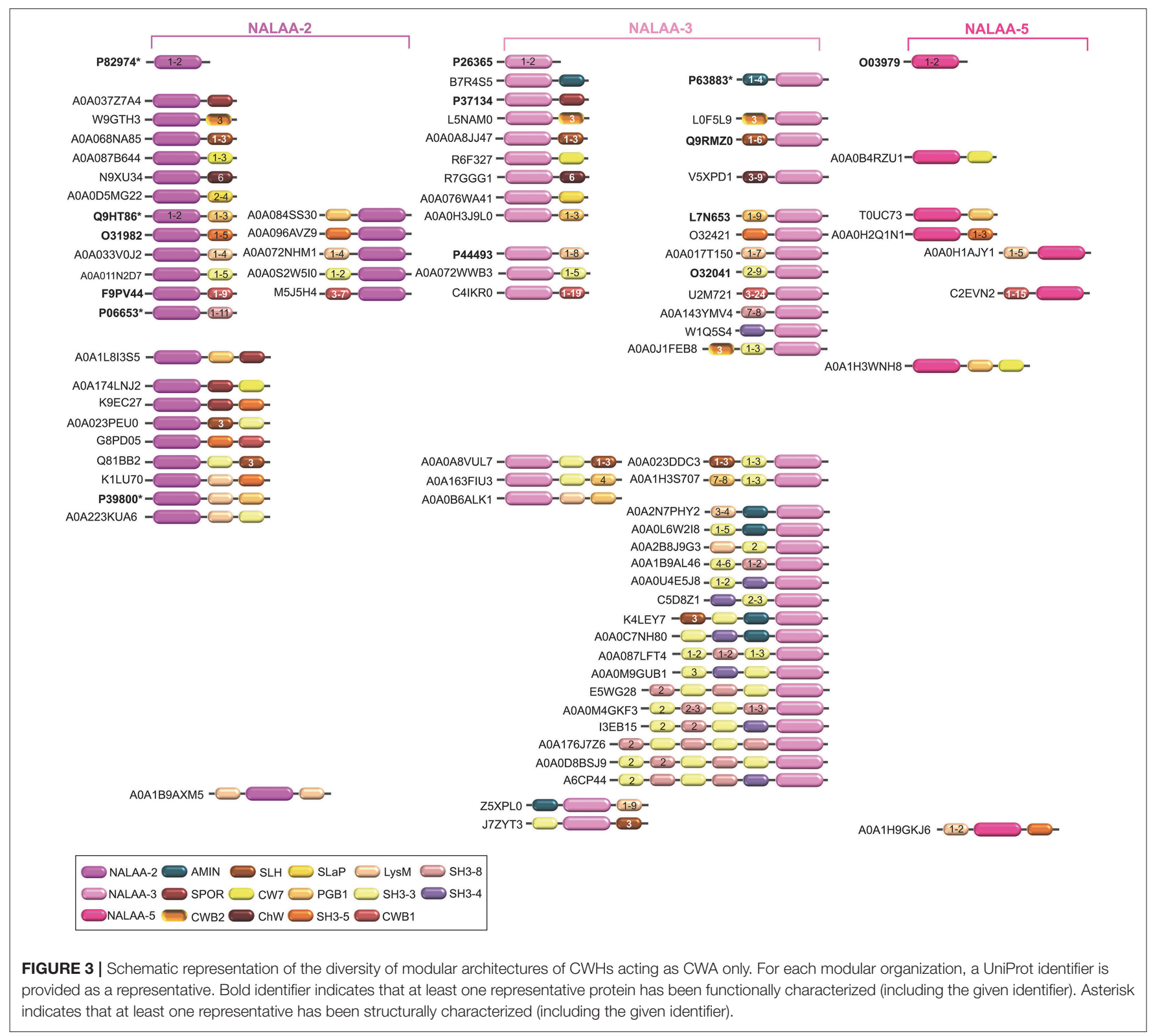

\section{$\mathrm{N}$-acetylmuramoyl-L-alanine amidase of Type 3 (NALAA-3)}

The NALAA-3 domain is approximately 175 amino acids long (IPR002508). In E. coli, the NALAA-3 AmiA and AmiC were shown to result in the release of the L-Ala-D-GlumDAP tripeptide and L-Ala-D-Glu-mDAP-D-Ala tetrapeptide. Like NALAA-2, NALAA-3 is a zinc-dependent amidase, which structure has been solved (Zoll et al., 2012; Rocaboy et al., 2013; Buttner et al., 2014).

\section{$\mathrm{N}$-acetylmuramoyl-L-alanine amidase of Type 5 (NALAA-5)}

The NALAA-5 domain is around 140 amino acids long (IPR008044). Dp-1, a bacteriophage of Streptococcus pneumoniae belonging to Siphoviridae family, encodes a NALAA-5 CW degrading enzyme (Lopez et al., 1981; Garcia et al., 1983). It was the first pneumococcal CWH to be purified and biochemically characterized as a CWA, which was further demonstrated to require choline for full enzymatic activity (Garcia et al., 1983). No structural information is as yet available for this CWA family.

\section{Cell Wall Glycosidases (CWG, EC 3.2.1)}

Glycosidases catalyse the hydrolysis of the glycosidic linkage $(\mathrm{O}-, \mathrm{N}-$, and S-linked), leading to the formation of a glucide hemiacetal or hemiketal (Holtje, 1995; Vollmer et al., 2008b). Glycosidases can also be called glycoside or glycosyl hydrolases. Over the years, the number of families of glycosidases has grown steadily and currently there are 135 families according to the CAZyme (Carbohydrate Active Enzymes) database (CAZy; http://www.cazy.org). CW glycosidases (CWGs), also called PG glycosidases (PGGs), can be broadly differentiated 


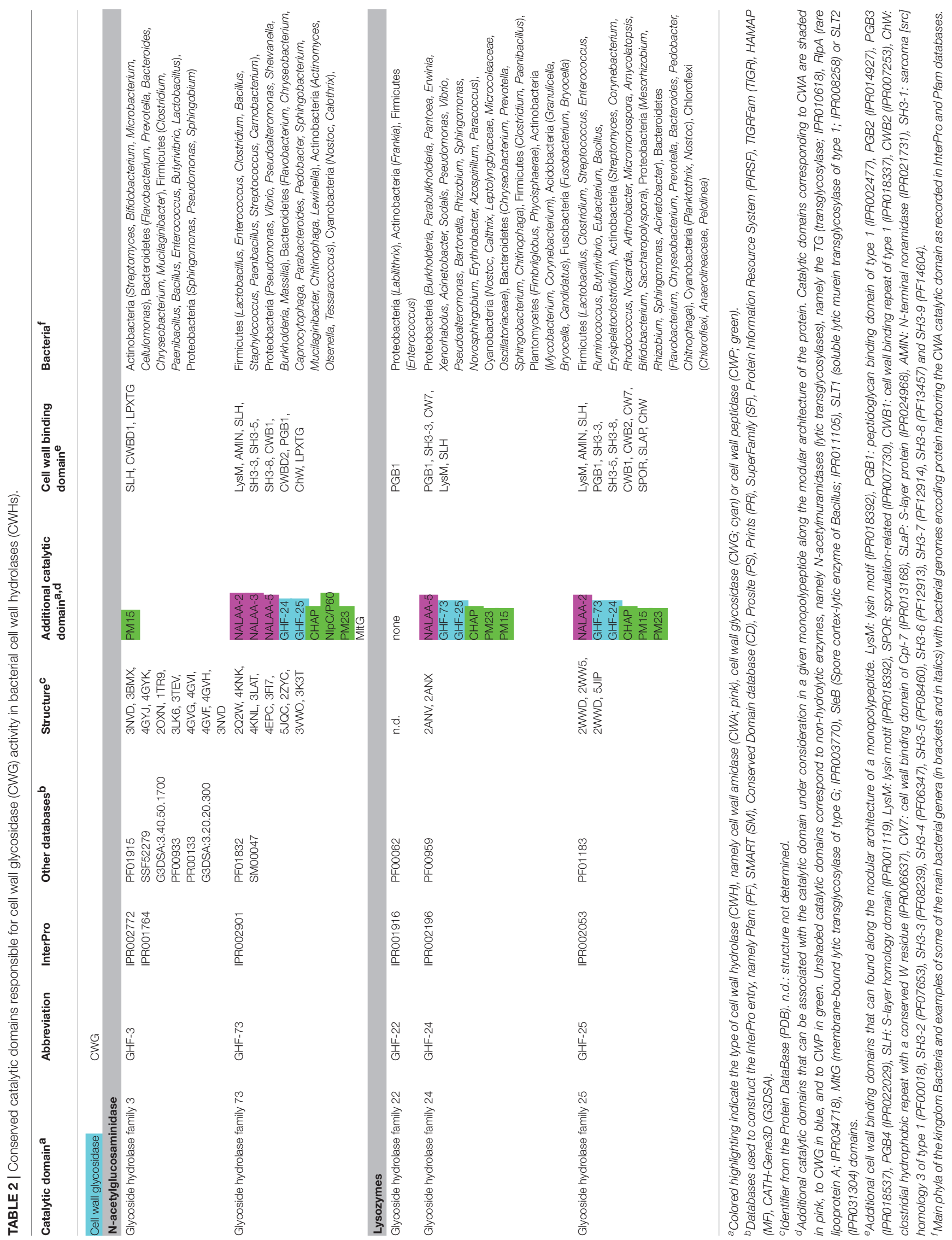




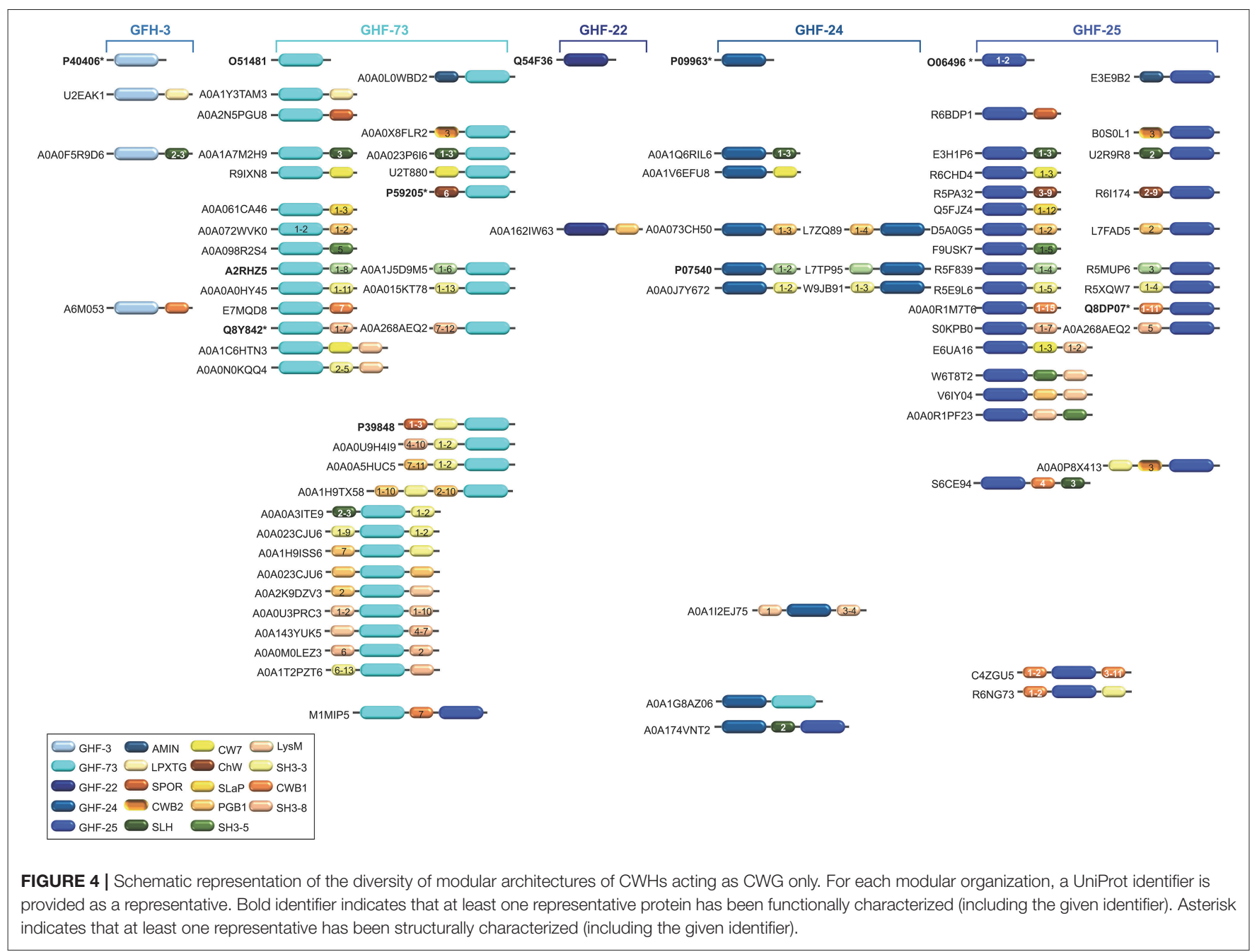

into (i) $\mathrm{N}$-acetylglucosaminidases, and (ii) lysozymes (Table 2 and Figure 4).

\section{$\mathrm{N}$-acetylglucosaminidases}

$\mathrm{N}$-acetylglucosaminidases hydrolyse the glycosidic bond in different oligosaccharide substrates including the CW, chitin and $\mathrm{N}$-glycans by cleaving specifically between $\mathrm{N}$-acetyl$\beta$-D-glucosamine residues and contiguous monosaccharides (Karamanos, 1997). To date, two domains have been reported as involved in $\mathrm{N}$-acetylglucosaminidase activity, the (i) glycosyl hydrolase family 3 (GHF-3; IPR001764), and (ii) glycosyl hydrolase family 73 (GHF-73; IPR001764) (Table 2).

\section{Glycosyl hydrolase family 3 (GHF-3)}

The GHF-3 domain is about 300 amino acids long (IPR001764) with a conserved Asp-His dyad is involved in CW lysis (Litzinger et al., 2010). NagZ (N-acetylglucosaminidase Z) from E. coli is one of the best characterized GHF-3 CWGs, which cleaves the GlcNAc-(1-4)-1,6-anhydro-MurNAc disaccharide (Cheng et al., 2000; Votsch and Templin, 2000; Van Heijenoort, 2001). It is active on both monomer and dimer muropeptides and is specific for the $\beta$ linkage. In B. subtilis, the NagZ ortholog requires CWA
AmiE to release MurNAc efficiently by sequential hydrolysis of muropeptides (Litzinger et al., 2010). NagZ from Vibrio cholerae was the first GHF-3 enzyme to be solved at structural level (Stubbs et al., 2007). As in many glycosyl hydrolases, it features a $(\beta / \alpha)_{8}$ barrel fold, known as a TIM barrel, with a large cavity containing the active catalytic site formed of an Asp-Glu dyad. However, structural investigation with NagZ from B. subtilis revealed a unique Asp-His catalytic mechanism (Litzinger et al., 2010). Interestingly, this enzyme contains an additional GHF-3 C-terminal domain (IPR002772) but the catalysis appears to rely only on N-terminal TIM-barrel domain (Varghese et al., 1999). Besides, the loop, where the catalytic His is located, undergoes significant structural changes during the binding of the substrate and catalysis (Bacik et al., 2012).

\section{Glycosyl hydrolase family 73 (GHF-73)}

The GHF-73 domain is around 80 amino acids long (IPR002901) where the active catalytic site is formed by a tetrad of Tyr-AlaThr-Asp amino acid residues together with a highly conserved glutamic acid residue (Huard et al., 2004; Inagaki et al., 2009). The first structure of a GHF-73 enzyme was obtained from Auto (autolysin) from Listeria monocytogenes (Bublitz et al., 2009). It 
revealed the mechanism of autoinhibition via the occlusion of the substrate binding cleft by an $\mathrm{N}$-terminal $\alpha$-helix. As confirmed in the other solved structures for this glycosyl hydrolase family (Hashimoto et al., 2009; Maruyama et al., 2010), Glu appears as the catalytic residue in the active site of LytB in S. pneumoniae (Bai et al., 2014).

\section{Lysozymes}

Lysozymes (also sometimes referred as $\mathrm{N}$-acetylmuramidases) and lytic transglycosylases (LTGs) cleave the same $\beta 1,4$-glycosidic bond but in two different ways. While its hydrolysis by lysozymes result in a product with a terminal reducing MurNAc residue without a ring, LTGs are not hydrolases but cleave the bond between MurNAc and GlcNAc with the concomitant formation of a 1,6-anhydro ring at the MurNAc residue (Herlihey and Clarke, 2017). Lysozymes are generally categorized into at least five different classes, i.e., C (chicken type), G (goose type), P (Bacteriophage lambda), F (fungi), and B (bacteria) (Jolles, 1996; Pei and Grishin, 2005; Vollmer et al., 2008b; Callewaert and Michiels, 2010; Callewaert et al., 2012). In bacteria, lysozymes remain poorly characterized but three conserved domains are currently recognized, i.e., the (i) glycosyl hydrolase family 22 (GHF-22; IPR001916), (ii) glycosyl hydrolase family 24 (GHF24; IPR002190) and (iii) glycosyl hydrolase family 25 (GHF-25; IPR002053) (Table 2).

\section{Glycoside hydrolase family 22 (GHF-22)}

The GHF-22 domain is about 120 amino acids long (IPR001916) and corresponds to lysozymes of type $\mathrm{C}$ almost uniquely found in species of the superkingdom Eukaryota (Mckenzie, 1996; Callewaert and Michiels, 2010). However, homologous sequences were recently identified in some bacterial species (Yamamoto et al., 2014; D'angelo et al., 2016) (Table 2).

\section{Glycoside hydrolase family 24 (GHF-24)}

The GHF-24 domain is approximately 110 amino acids long (IPR002190) and corresponds to phage lysozymes (type P), which structure has been solved only for the bacteriophage P22 lysozyme (Mooers and Matthews, 2006). Together with GHF-22, the function and activity of GHF-24 enzymes still await to be investigated in bacteria.

\section{Glycoside hydrolase family 25 (GHF-25)}

The GHF-25 domain is about 180 amino acid long (IPR002053) and corresponds to the lysozymes of type B such as Cpl-1, produced by the phage $\mathrm{Cp}-1$, which specifically lyses several serotypes of S. pneumoniae (Perez-Dorado et al., 2007; Doehn et al., 2013). LytC from S. pneumoniae was the first GHF25 enzyme whose structure has been solved (Perez-Dorado et al., 2010). Conformational changes appear to play a key role in PG hydrolysis, especially in the control of the enzymatic activity. In SleM from Clostridium perfringens, dimerisation was demonstrated to be of great importance for the enzymatic activity, most certainly by facilitating the positioning of substrate respective to the catalytic site (Al-Riyami et al., 2016).

\section{Cell Wall Peptidases (CWPs, EC 3.4)}

A CW peptidase (CWP) cleaves the amide bonds between amino acids in PG (Holtje, 1995). CWPs, also called PG peptidases (PGPs), can be discriminated between endopeptidases or carboxypeptidases depending on their substrate specificity, as they respectively cleave within the PG peptide or remove the C-terminal amino acids. While D,L- and L,D-peptidases cleave between L- and D-amino acids, D,D-peptidases cleave between two D-amino acids (Smith et al., 2000). To date, 10 different types of domains have been reported for CWPs, the (i) cysteine histidine-dependent amidohydrolases/peptidases (CHAP; IPR007921), (ii) new lipoprotein C/protein of $60-\mathrm{kDa}$ (NlpC/P60; IPR000064), (iii) peptidase M14 (PM14; IPR005073), (iv) peptidase M15 (PM15; IPR000755), (v) peptidase M23 (PM23; IPR016047), (vi) peptidase M74 (PM74; IPR005073), (vii) peptidase S11 (PS11; IPR001967), (viii) peptidase S13 (PS13; IPR000667), (ix) transpeptidase (TP, IPR005490), and (x) peptidase S66 (PS66; IPR003507) (Table 3 and Figure 5).

\section{Cysteine Histidine-Dependent Amidohydrolases/Peptidases (CHAP)}

The CHAP domain is around 120 amino acids long (IPR007921) with the unique feature to be potentially involved in two different CW cleavage activities (Bateman and Rawlings, 2003; Rigden et al., 2003). As a peptidase, it cleaves between D-alanine and the first glycine of the pentaglycine cross-bridge, but it can also act as an amidase by cleaving the chemical bond between MurNAc and $\mathrm{L}$-alanine at the $\mathrm{N}$-terminal of the stem peptide (Bateman and Rawlings, 2003; Rigden et al., 2003). Depending on the CHAPproteins, some have been described as having only a peptidase activity (e.g., LysK), only amidase activity (e.g., Skl), or both (e.g., LytN) (Llull et al., 2006; Becker et al., 2009; Frankel and Schneewind, 2012). In phage proteins, the CHAP domain is mostly positioned in the $\mathrm{N}$-terminal region, whereas in bacterial proteins it is systematically positioned at the C-terminal (Zou and Hou, 2010). The bacteriophage LysK was active on purified PG of a number of pathogenic strains including a wide range of staphylococci (O'flaherty et al., 2005; Becker et al., 2009). Resolution of the CHAP structure revealed a calcium-binding site, where calcium ion appeared to play a key role in the switch from active to inactive states (Gu et al., 2014; Sanz-Gaitero et al., 2014; Keary et al., 2016; Broendum et al., 2018). In CHAP SSP0609 from S. saprophyticus, a highly-conserved Cys-His-GluAsn tetrad relaying the active site was further evidenced (Rossi et al., 2009). While a set of hydrophobic residues forming a large cavity that would confer specificity to the binding site was lacking in the immediate vicinity of the active site, two Tyr aromatic residues likely play a role in substrate anchoring.

\section{New Lipoprotein C/Protein of 60-kDa (NIpC/P60)}

The NlpC/P60 domain is about 100 amino acids long (IPR000064) and proteins of this superfamily are ubiquitous papain-like cysteine peptidases involved in the catalysis of the $N$-acetylmuramate-L-alanine or $\mathrm{D}$ - $\gamma$-glutamyl-mesodiaminopimelate linkages (Anantharaman and Aravind, 2003). Four major families have been identified, namely (i) the P60-like family, (ii) the AcmB/LytN-like family, (iii) the YaeF/Poxvirus 


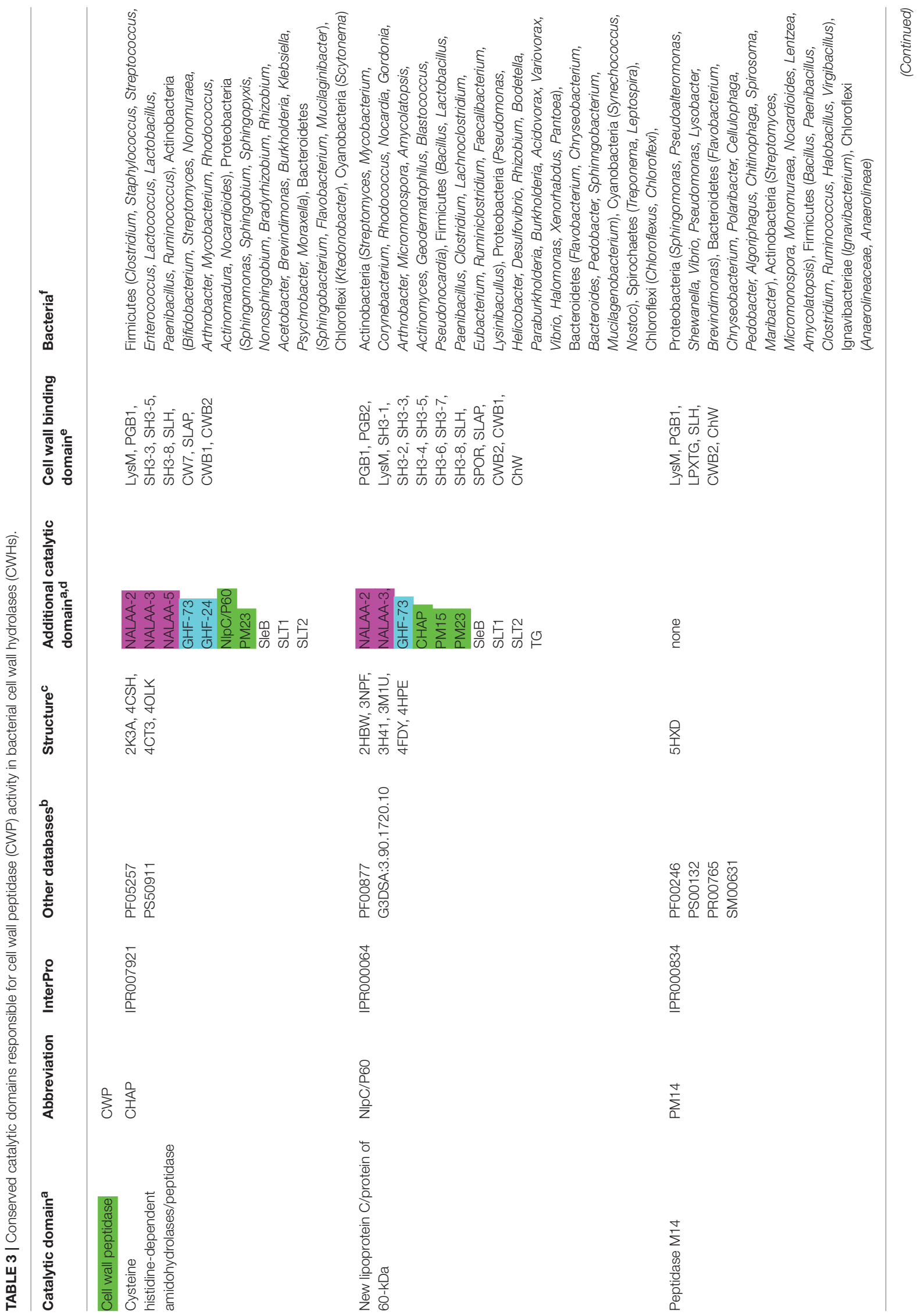




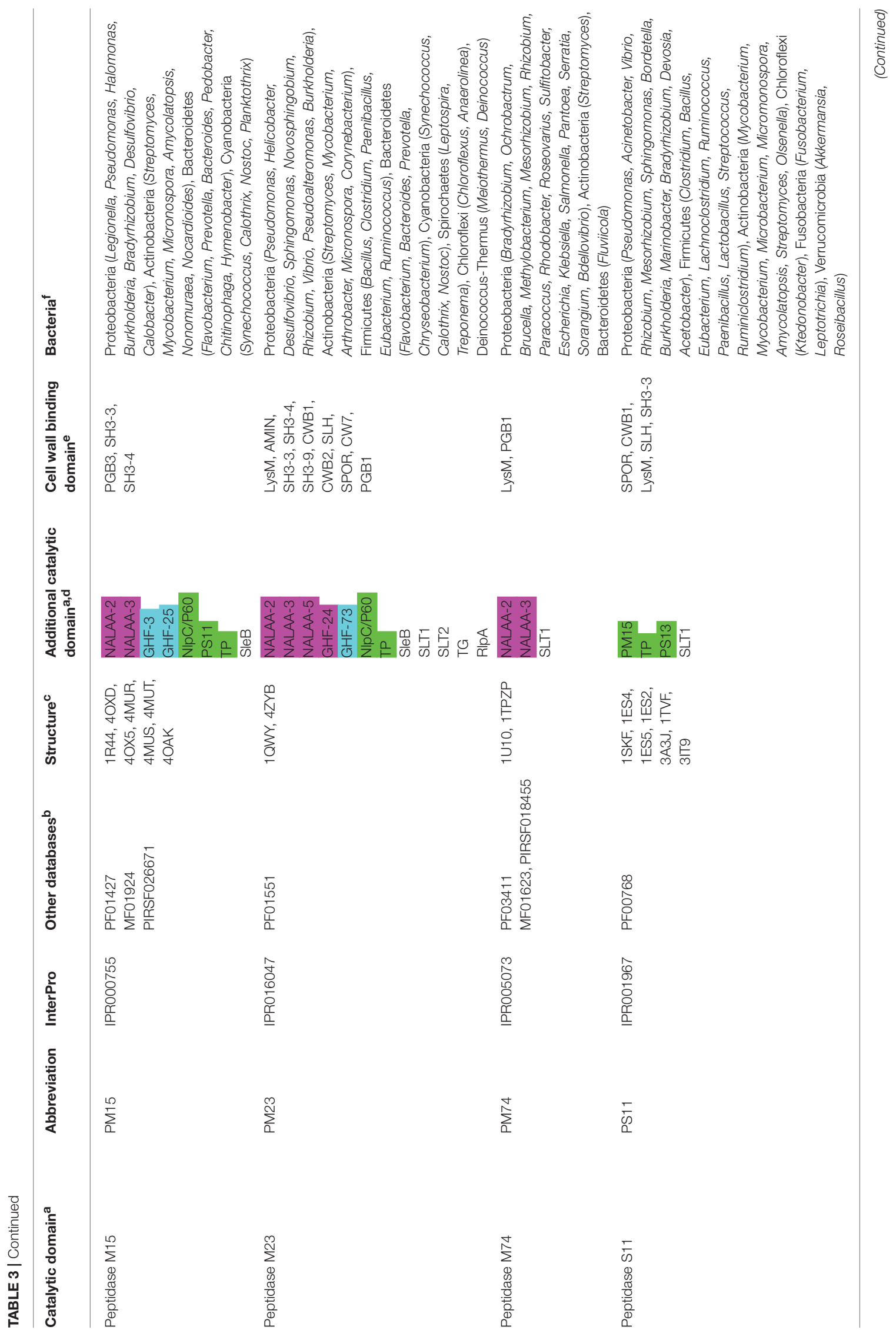




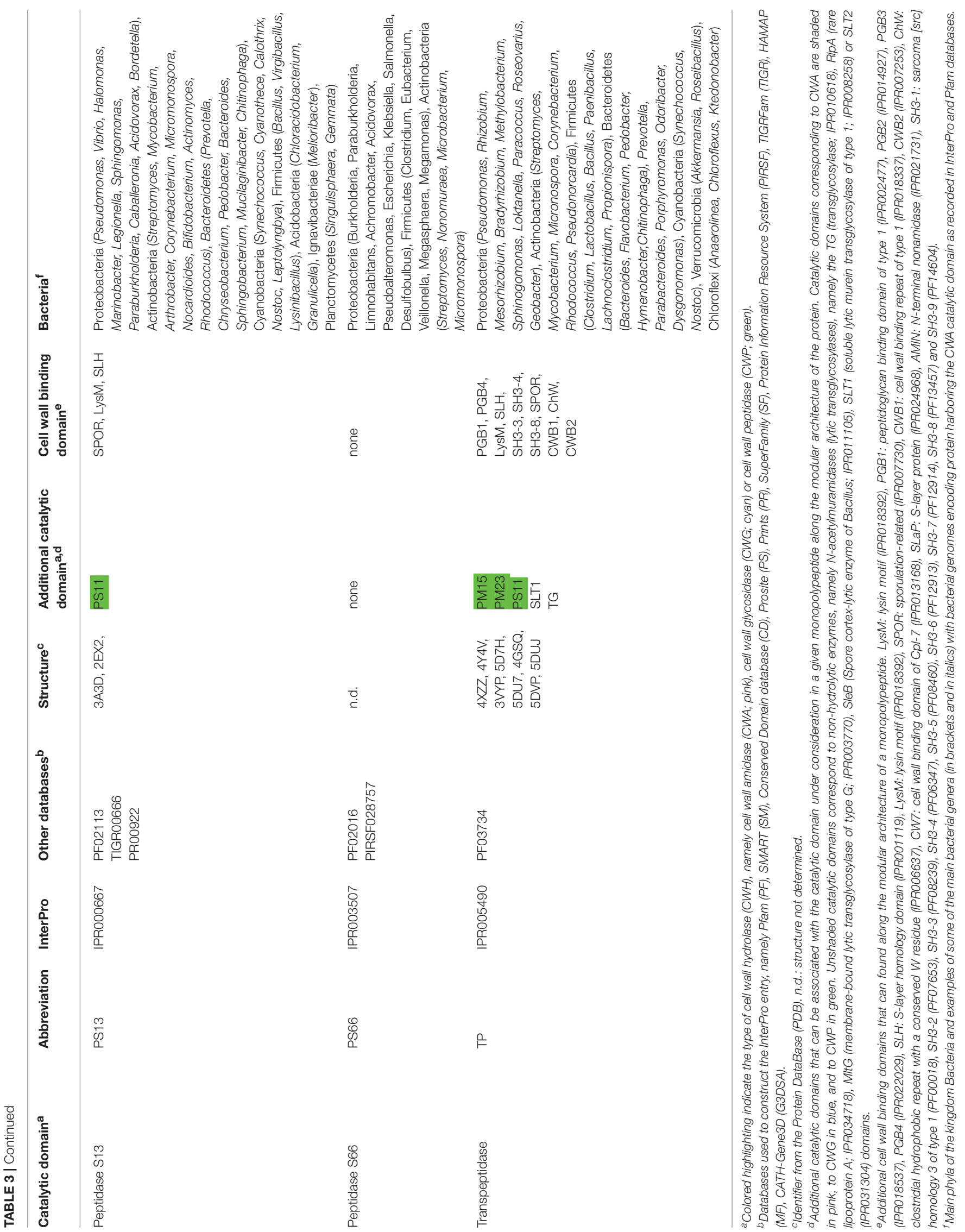




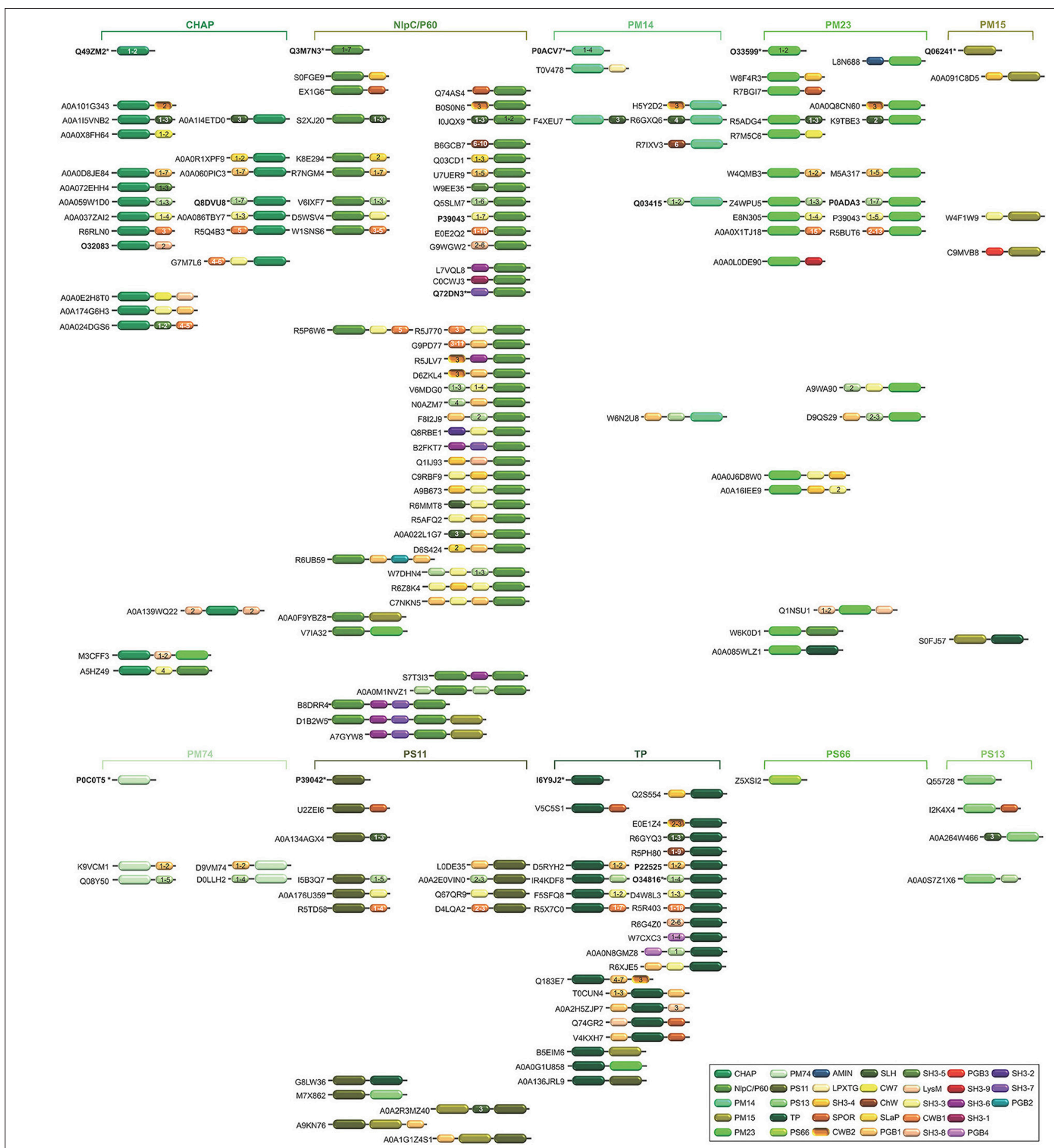

FIGURE 5 | Schematic representation of the diversity of modular architectures of CWHs acting as CWP only. For each modular organization, a UniProt identifier is provided as a representative. Bold identifier indicates that at least one representative protein has been functionally characterized (including the given identifier). Asterisk indicates that at least one representative has been structurally characterized (including the given identifier).

G6R family, and (iv) the lecithin retinol acyltransferase-like (LRAT-like) family (Anantharaman and Aravind, 2003). These two latter enzyme families contain a circularly permuted catalytic domain where the relative positions of the cysteine and histidine/polar residue of the conserved catalytic triad are swapped in the primary sequence (Anantharaman and
Aravind, 2003). In B. subtilis, LytF and LytE, which belong to the P60-like family, break the linkage of m-diaminopimelic acid of the PG (Yu et al., 2016). Structure determination of NlpC/P60 domain in CwlT from Clostridioides difficile, previously known as Clostridium difficile or Peptoclostridium difficile (Yutin and Galperin, 2013; Lawson et al., 2016), 
revealed a conserved Cys-His-His-Tyr active site specific to tetrapeptide (Xu et al., 2014). Switch between catalysis in the closed state to the substrate entry or product release in the open state is likely regulated by a side chain above the catalytic Cys residue.

\section{Peptidase M15 (PM15)}

The PM15 domain is approximately 200 amino acids long (IPR000755) and can be further discriminated into four subfamilies, namely from PM15A to PM15D. In Enterococcus faecium, the structure of the D-Ala-D-Ala dipeptidase VanX has been solved and revealed a $\mathrm{Zn}$-dependent catalytic mechanism (Bussiere et al., 1998). In contrast, the D,D-carboxypeptidase VanY is active against pentapeptide but lacks activity against dipeptides (Wright et al., 1992). The D,D-carboxypeptidase VanXYc from Enterococcus gallinarum, however, can further hydrolyse pentapeptides (Meziane-Cherif et al., 2014). Following structural and biochemical analyses, the molecular basis of this dual specificity was unraveled and appeared to result from the flexibility of a mobile cap region over the catalytic site, which allows the switch between di- and pentapeptide hydrolysis (Meziane-Cherif et al., 2014). Such a structural element would be lacking from VanY enzymes. While structure comparison revealed similarity in the catalytic sites of VanXY and VanX, differences were pinpointed at the D-Ala-D-Ala binding sites especially for a second cavity present in VanXY but with no equivalent in VanX.

\section{Peptidase M23 (PM23)}

The PM23 domain is around 100 amino acids long (IPR016047). Lysostaphin from Staphylococcus simulans is one of the best studied PM23. In its active form, lysostaphin cuts the peptide bond between the third and fourth glycine residues of the pentaglycine cross-link in the PG of Staphylococcus (Schneewind et al., 1995). The active enzyme shares structural similarity with Ale-1 and LytM (Sabala et al., 2014). In Staphylococcus capitis, however, the N-terminal repeats of the lysostaphin homolog Ale1 are not processed post-translationally (Sugai et al., 1997; Lu et al., 2006). In S. aureus, LytM is produced as a latent CWH, where the occluding region and $\mathrm{N}$-terminal domain need to be removed for its activation (Sabala et al., 2012). Following resolution of the enzyme structure (Odintsov et al., 2004), the importance of $\mathrm{Zn}^{2+}$ cation in the catalysis was confirmed, whereas the active site appeared to be located at the bottom of an extended, long and narrow groove, partially filled up by a loop, which would constitute the substrate-binding cleft (Firczuk et al., 2005; Grabowska et al., 2015). Beside the preferential glycineglycine bonds, characterization of several PM23 suggested that they can also be less frequently active against alanine-glutamine bonds (Schindler and Schuhardt, 1964; Horsburgh et al., 2003a).

\section{Peptidase M74 (PM74)}

The PM74 domain is about 230 amino acids long (IPR005073). The PM74 D,D-endopeptidase MepA from E. coli cleaves the Dalanyl-meso-2,6-diamino-pimelyl amide bond in PG (Keck et al., 1990; Van Heijenoort, 2001). Structural investigations further revealed the enzymatic activity of MepA was $\mathrm{Zn}$ dependent and consequently sensitive to metal chelators (Keck et al., 1990; Van Heijenoort, 2001; Marcyjaniak et al., 2004).

\section{Peptidase S11 (PS11)}

The PS11 domain is approximately 235 amino acids long (IPR001967) and is systematically associated with another C-terminal domain (IPR012907), which is organized into a sandwich of two anti-parallel $\beta$-sheets. The function of this $\mathrm{C}$-terminal domain is unknown, but it could mediate interaction with other CW synthesizing enzymes (Davies et al., 2001). The PS11 is involved in hydrolysis of the D-Ala-D-Ala bond and is present in several penicillin-binding proteins (PBPs) (Van Heijenoort, 2001; Macheboeuf et al., 2006). Investigation of the enzymatic mechanism stressed the importance of the Lys-Ser-Cys at the catalytic site (Fonze et al., 1999; Rhazi et al., 2003).

\section{Peptidase M14 (PM14)}

The PM14 domain is about 270 amino acids long (IPR005073). Together with PS13 and PS66 domains, little experimental work has been dedicated to PM14 domain. In E. coli, the PM14 MpaA hydrolyses the $\gamma$-D-glutamyl-diaminopimelic acid bond in the murein tripeptide L-alanyl- $\gamma$-D-glutamyl-mesodiaminopimelic acid (Uehara and Park, 2003). Structural analysis revealed the entrance and binding of the substrate into the active groove was mediated by a loop with critical Tyr-Asp residues (Ma et al., 2017).

\section{Peptidase S13 (PS13)}

The PS13 domain is around 430 amino acids long (IPR000667). The PS13 PBP4 from E. coli exhibits both D,D-carboxypeptidase and D,D-endopeptidase activities (Van Heijenoort, 2011).

\section{Peptidase S66 (PS66)}

The PS66 domain is about 315 amino acids long (IPR003507). The PS66 LdcA from E. coli is a L,D-carboxypeptidase releasing the terminal $\mathrm{D}$-alanine residue from the tetrapeptide L-Ala- $\gamma$-DGlu-meso-A $A_{2}$ pm-D-Ala (Templin et al., 1999).

\section{Transpeptidase (TP)}

The TP domain is approximately 120 amino acids long (IPR005490). The L,D-transpeptidase LdtMt2 from Mycobacterium tuberculosis harbors a TP domain and has been the subject of intense structural investigations, especially for the study of drugs blocking the enzyme activity through PG cross-linking (Kim et al., 2013; Li et al., 2013; Bianchet et al., 2017; Kumar et al., 2017; Gokulan et al., 2018). In E. coli, YbiS, ErfK, YcfS, YcbB, and YnhG also harbor a TP domain but exhibit both L,D-transpeptidase and L,D-carboxypeptidase activities (Magnet et al., 2008; Van Heijenoort, 2011). These five enzymes possess a sole Cys residue essential for activity. While YbiS, ErfK and YcfS enable to cross-link lipoprotein to PG, YcbB and $\mathrm{YnhG}$ catalyse the cross-linking of mDAP to form direct meso-diaminopimelate (DAP-DAP, also called linkage of 3-3 type) (Sanders and Pavelka, 2013). Actually, the majority of the cross-linking of the stem peptides involves penicillin-binding proteins (PBPs) with D,D-transpeptidase activity (IPR001460) and corresponds to the 4-3 type, where a D-alanine residue at the fourth position of the peptide stem links at a mDAP at 
the third position of an adjacent peptide stem (Glauner et al., 1988; Arbeloa et al., 2004). While Csd6 from Helicobacter pylori clearly possesses a TP domain, it would not function as a L,D-transpeptidase at all but as a L,D-carboxypeptidase (Kim et al., 2015). This stresses the need for further investigations to gain insight in the diversity of the TP domain, most certainly into subfamilies and probably a redefinition of this domain family.

\section{The Diversity of the Modular Architecture of Cell Wall Hydrolases}

Besides the different catalytic domains involved in PG hydrolysis and reviewed here above, numerous CWHs have CW binding domains (Table 1 and Figures 3-5). In bacteria, several conserved domains have been reported as involved in covalent or non-covalent binding of proteins to $\mathrm{CW}$ components (Desvaux et al., 2006, 2018; Tables 1-3). The optimal type and number of anchoring domains required for maximum binding differs from one protein to another (Visweswaran et al., 2014). As a general rule, these domains allow binding of the enzymes to the $\mathrm{CW}$ at an adequate concentration and properly position the active site toward the PG substrate site for formation of an efficient enzyme-substrate complex (Steen et al., 2005; Bosma et al., 2006; Shao et al., 2012). Because of close spatial proximity, the released hydrolysed products can be readily and efficiently transported into the cell for recycling (Ozdemir et al., 2012).

LysM (IPR018392), one of the most frequent CW binding domains found in CWHs, is found at the $\mathrm{N}$ - or C-terminal of a protein (Buist et al., 2008). The number of domains found in a $\mathrm{CWH}$ varies from one to 12 , and these domains are generally separated by serine-threonine-asparagine rich intervening sequences (Bateman and Bycroft, 2000; Visweswaran et al., 2014). When present, PGB1 (IPR002477) is usually found in a single copy at the $\mathrm{N}$ - or C-terminal; although up to nine repeats can be found in some proteins (Desvaux et al., 2006). The SLH (S-layer homology domain; IPR001119) is generally found at the C-terminal of CWHs. In the NALAA-3 AmiC from E. coli, the AMIN (N-terminal nonamidase; IPR021731) domain allows proper localization of the enzyme at the division site through binding to the PG (Rocaboy et al., 2013).

In CWHs, nine different types of $\mathrm{SH} 3$ (sarcoma [src] homology 3; IPR003646) domains can be found, from SH3 of type 1 (SH3-1) to SH3-9 (Tables 1-3). The SH3 domains can be found in the $\mathrm{N}$ - or $\mathrm{C}$-terminal region of a $\mathrm{CWH}$ (Figures 36). This domain contains five $\beta$-strands forming two orthogonal anti-parallel $\beta$-sheets of two and three $\beta$-strands each (D'aquino and Ringe, 2003; Desvaux et al., 2006, 2018). In PlyTW (phage Twort endolysin), it has been demonstrated that loss of SH3 domain results in an $\sim 10$-fold reduction in enzymatic activity (Becker et al., 2015). Deletion analysis of SpAE (staphylococcal phage 2638A endolysin) indicates that the NALAA-2 domain confers most of the lytic activity and requires the full SH3 domain for maximal activity (Abaev et al., 2013). Actually, loops from SH3 domains can dock into the ends of the active site groove of the catalytic site, remodel the substrate binding site and modulate substrate specificity (Xu et al., 2015).
Actually, more than one CW binding domain can be found in some CWHs (Figures 3-6). While it can be hypothesized that such combinations are beneficial for catalysis, much remains to be learned about their effect on PG hydrolysis. Studies have yet to be made of the structure-function relationships and structural constraints regarding the large varieties of combinations between different catalytic domains and/or CW binding domains (Alcorlo et al., 2017; Broendum et al., 2018).

The different catalytic domains reviewed above can be found individually or in combination in various CWHs (Tables 13 and Figure 6). CWHs with only one catalytic domain do not necessarily have a CW binding domain but very often CWHs harboring an additional catalytic domain also have a CW binding domain (Visweswaran et al., 2014). Numerous different combinations of CWA, CWG, and CWP domains can be found, although the diversity of associations of CWA or CWG domains with CWP domains or the simultaneous presence of CWA, $\mathrm{CWG}$, and CWP domains in a single $\mathrm{CWH}$ is rare (Figure 6).

Most CWAs exhibit only one catalytic domain, either NALAA-2, NALAA-3, or NALAA-5 (Figure 3); no CWA combining two types of amidase catalytic domain has been reported to date (Table 1). However, in some CWHs, these CWA domains can be found in association with either a CWG domain, especially GHF-73, or a peptidase domain, such as PM23 (Albrecht et al., 2012) (Figure 6). As in CwlA from $B$. subtilis (Foster, 1993), NAALA-2 can be found in association with GHF-25. The major CWHs AtlA from S. aureus and AtlE from $S$. epidermidis are synthesized as propeptides with a NALAA-2 domain together with a GHF-73 domain (Oshida et al., 1995; Heilmann et al., 1997; Albrecht et al., 2012). The propeptide is cleaved off by an extracellular protease generating two extracellular CWHs, namely a $51 \mathrm{kDa}$ endo$\beta$-N-acetylglucosaminidase and a $62 \mathrm{kDa} \mathrm{N}$-acetylmuramoylL-alanine amidase, which are independently involved in the partitioning of daughter cells after cell division (Yamada et al., 1996; Götz et al., 2014). Regarding peptidase domains associated with an amidase domain, SpAE has a N-terminal PM23 domain together with a central NALAA-2 domain (Abaev et al., 2013). Deletion analysis indicates that the NALAA-2 domain confers most of the lytic activity (Abaev et al., 2013). In contrast, in LytA from $S$. aureus where a N-terminal CHAP domain is associated with a central NALAA-2 domain, the lytic activity is prominently conferred by the CHAP domain (Havarstein et al., 2006). By generating a truncation in the homologous CWH LysK (from bacteriophage $\mathrm{K}$ in Lactococcus lactis), where only the first 165 amino acids are kept, an activity twofold higher than that of the native protein was observed (Rigden et al., 2003; Horgan et al., 2009). The endolysin PlyTW from bacteriophage Twort has a similar architecture to LytA and LysK, and its CHAP domain alone is sufficient and necessary for cell lysis but the NALAA-2 domain alone is insufficient (Becker et al., 2015).

CWG can either display one glycosidase domain alone or in association with a peptidase domain (Figure 6). While only the GHF-25 and GHF-73 glycosidase domains can be found in association with an amidase domain, several peptidase domains can be associated with glycosidase. Among the four CWHs from L. lactis, AcmB (N-acetylmuramidase type B) harbors a central 


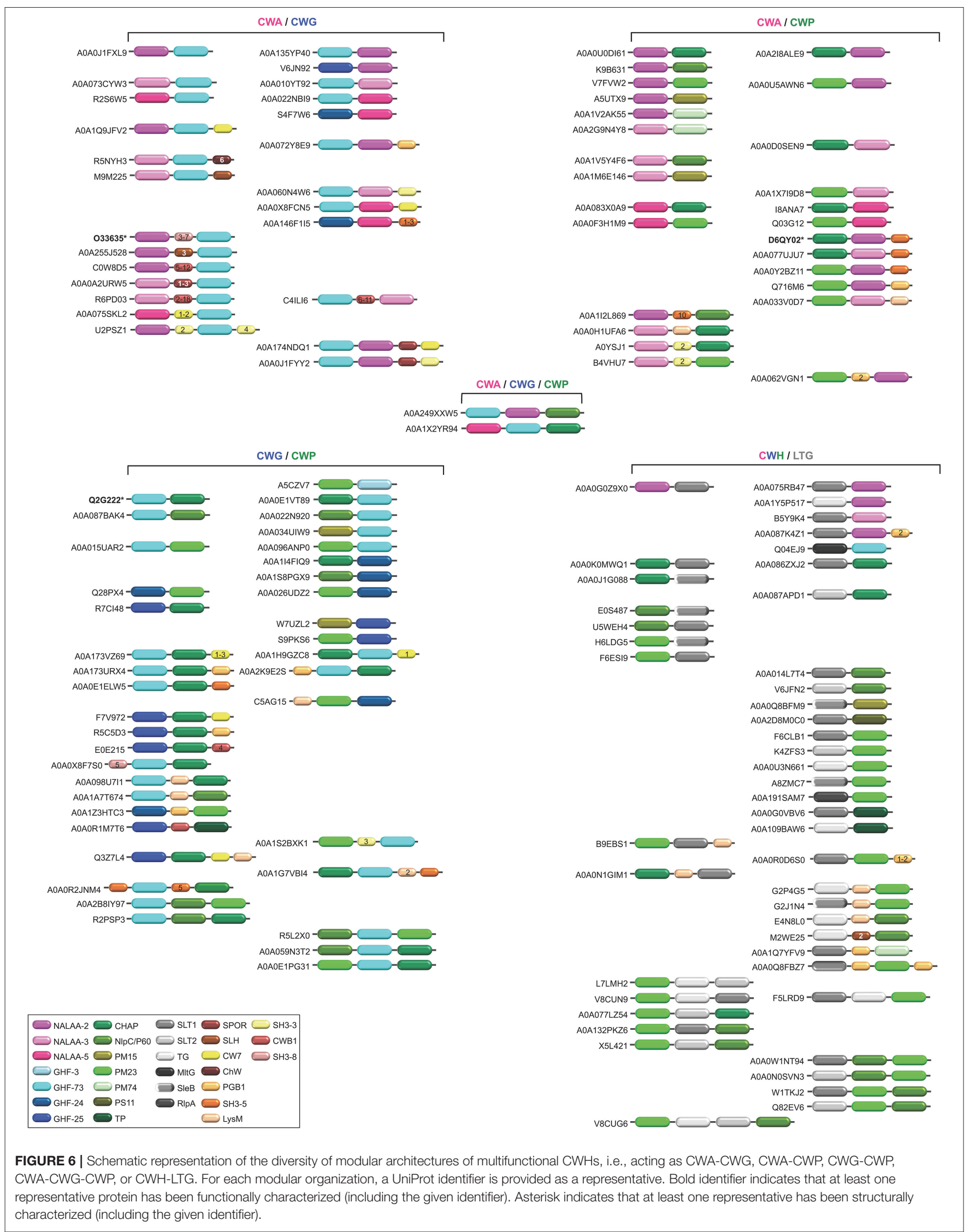


GHF-73 domain and a C-terminal CHAP domain (Huard et al., 2003, 2004; Visweswaran et al., 2013). Qualitatively, a truncated version of the enzyme lacking the CHAP domain seems less efficient than the enzyme with the dual catalytic sites for CW hydrolysis (Huard et al., 2003). Considering the low pI (5.03) of the mature protein, and that a hydrolytic activity can only be detected at acidic $\mathrm{pH}$ in renaturing conditions, this suggests that interaction with the negatively charged $\mathrm{CW}$ is favored by a positive or neutral charge of the protein. Unlike CWAs, some CWGs and CWPs can combine two different types of glycosidase or peptidase catalytic domains, e.g., PS11 and PS13 (Tables 2, 3 and Figure 7). However, the functional characterization and benefit for enzymes with such a modular architecture has not been yet investigated. With regards the wealth of diverse combinations, much remains to be learned about the inhibiting and synergistic effects of the interactions between amidase, glucosidase and peptidase domains in a monopolypeptidic $\mathrm{CWH}$.

Of interest, some CWHs can also harbor additional catalytic domains involved in CW degradation but unrelated to hydrolases, namely the LTGs (Figure 6). In fact, the molecular reaction mechanism for LTGs does not involve water (Höltje et al., 1975). Based on conserved sequence motifs (Herlihey and Clarke, 2017), LTGs are discriminated between SLT1 (soluble lytic murein transglycosylase of type 1; IPR008258), SLT2 (IPR031304), SleB (Spore cortex-lytic enzyme of Bacillus; IPR011105), TG (transglycosylase; IPR010618), MltA (membrane-bound lytic transglycosylase of type A; IPR005300), MltG (previously known as YceG; IPR003770) and RlpA (rare lipoprotein A; IPR034718) domains (Blackburn and Clarke, 2001; Scheurwater et al., 2008; Vollmer et al., 2008b; Li et al., 2012). Of note, LysG (IPR023346; PF13702) constitutes an additional LTG domain but further biochemical characterisations are still required to confirm this (Xu et al., 2014). While MtlA catalytic domain could never be found associated with any CWH domain, SLT1 can be found together with some CWA domains, namely NALAA-2 or NALAA-3, and/or some CWP domains, namely CHAP, NlpC/P60, PM23, and TP (Table 1). SLT2, TG and RLpA could only be found in some CWPs. Among CWGs, only MltG could be found in association with GHF-73.

\section{CELL WALL HYDROLASES FROM CELL DIVISION, THROUGH CELL WALL REARRANGEMENT, TO RECYCLING AND CELL LYSIS, UP TO COLLATERAL EFFECTS}

CWHs are an essential part of bacterial cell physiology. These ubiquitous enzymes have important roles in cell division and CW rearrangement in creating space within the PG to accommodate supramolecular structures for the secretion and assembly of flagella or pili (Scheurwater et al., 2008). PG recycling is tightly coordinated with its biosynthesis in a carefully controlled manner to prevent the loss of CW integrity, which would lead to cell lysis and bacterial death (Figure 7). Beyond bacterial growth and cell lysis, CWH activity can have side effects on a wide range of physiological functions from bacterial adhesion, biofilm formation, protein secretion, conjugation, virulence and immune response.

\section{Cell Division and Cell Wall Rearrangement}

In the course of bacterial cell growth, PG is biosynthesised through well-known anabolic pathways, including (i) the synthesis of MurNAc pentapeptide precursor (Barreteau et al., 2008; Sobhanifar et al., 2013), (ii) the attachment of the precursor to the membrane anchored lipid carrier completing the formation of the PG precursor lipid II (Bouhss et al., 2008), and (iii) the polymerisation of the PG by PBPs, glycosyltransferases, L,D- and D,D-transpeptidases after translocation of lipid II across the cytoplasmic membrane, (Sauvage et al., 2008; Typas et al., 2012). The majority of low molecular weight PBPs acts as D,Dcarboxypeptidases that help to control the extent of cross-linking through hydrolysis of the carboxy D-Ala-D-Ala peptide bond of a stem peptide (Scheffers and Pinho, 2005). D,D-carboxypeptidases remove terminal $\mathrm{D}$-Ala residues at position 5 of pentapeptides in the PG and regulate PG synthesis (Egan et al., 2015). For example, a S. pneumoniae mutant lacking the D,D-carboxypeptidase PBP3 forms aberrant septa and has a thickened CW, whereas an E. coli mutant lacking PBP5 has bent or even branched cell shapes (Nelson and Young, 2001; Vollmer et al., 2008b). PG growth or elongation requires the cleavage of covalent bonds by hydrolases to allow the newly attached material to be inserted in the layer without increasing its thickness (Typas et al., 2012; Vollmer, 2012). In E. coli, the three CWPs, Spr, YdhO (belonging to $\mathrm{NlpC} / \mathrm{P} 60$ ) and YebA (belonging to PM23), are collectively required for cell growth and PG incorporation (Singh et al., 2012). The depletion of these endopeptidases results in growth arrest and lysis in E. coli and prevents further incorporation of new PG (Vollmer, 2012).

In $B$. subtilis, the disruption of two D,L-endopeptidase genes $c w l O$ and $l y t E$ (belonging to $\mathrm{NlpC} / \mathrm{P} 60$ ) is lethal (Bisicchia et al., 2007). Inactivation of the LytF CWP harboring a Nlpc/P60 domain lead to slightly filamentous cells, whereas the lytF lytE double mutant forms extra-long chains (Ohnishi et al., 1999). In S. aureus, the Sle1 CWP with a CHAP is required for cell separation (Kajimura et al., 2005). However, it is not yet known how the CWHs required for cell growth are positioned and regulated and how their depletion results in a halt in PG incorporation. In accordance with the "makebefore-break" strategy (Koch and Doyle, 1985), a new threefor-one growth mechanism has been proposed (Holtje, 1996, 1998), namely for every three new PG strands inserted in the $\mathrm{CW}$, one old strand is replaced. The existence of multienzyme complexes in $E$. coli was proposed to combine the activities of PG synthases (transpeptidases and transglycosidases) and PG hydrolases (Holtje, 1996, 1998; Scheffers and Pinho, 2005). Affinity chromatography with immobilized lytic enzymes such as MltA, Slt70 or MltB has indeed identified interactions with PG synthases (Vollmer et al., 2008a).

PG cleavage is also required for reductive cell division and cell separation. E. coli has 13 periplasmic CWHs that can collectively cleave almost any glycoside, peptide or amide bond (Vollmer et al., 2008b). No single hydrolase gene knockout prevents growth of E. coli, probably owing to high redundancy. In fact, multiple 


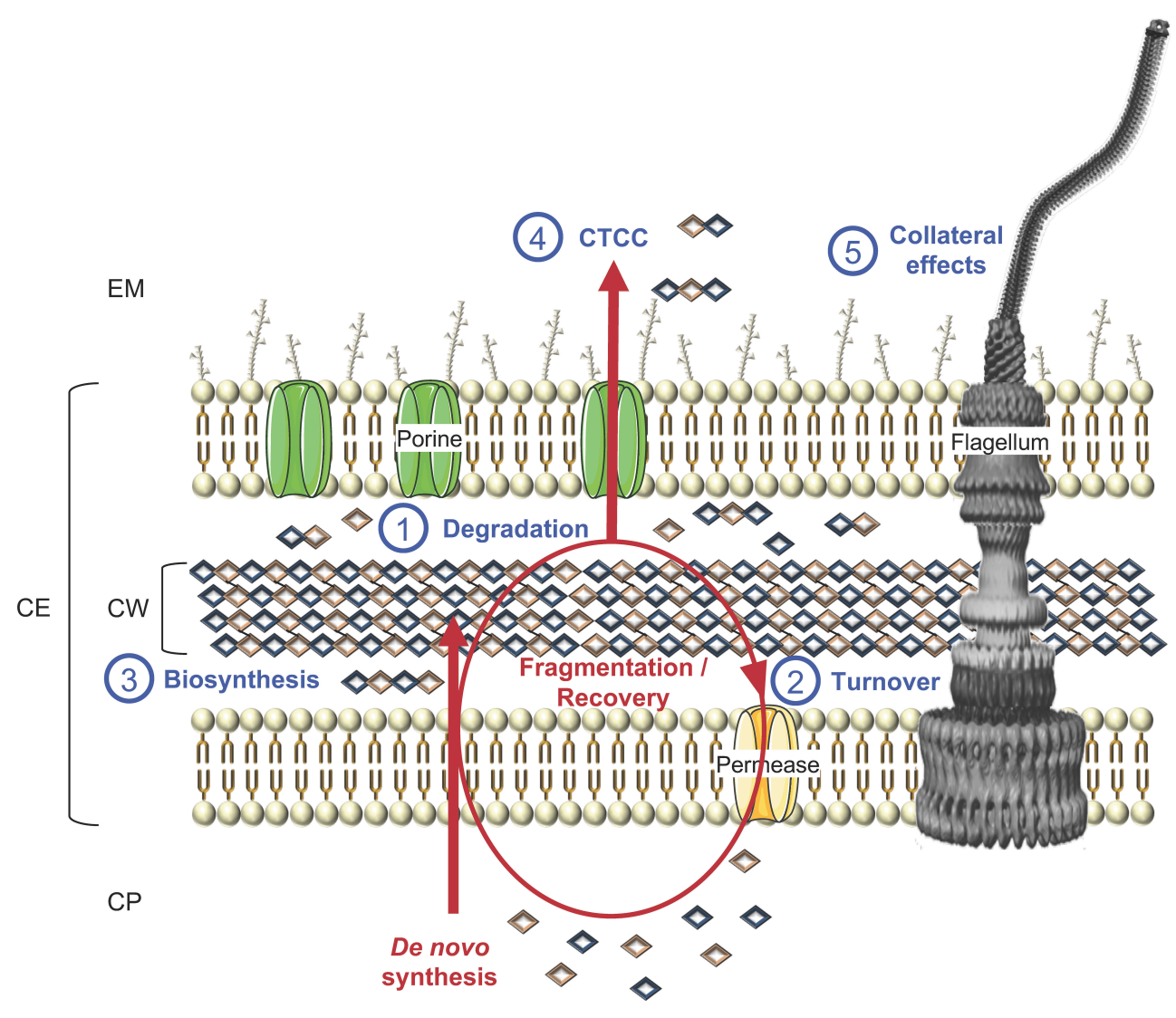

FIGURE 7 | Schematic representation of cell wall biosynthesis and recycling, exemplified in a LPS-diderm bacterial cell. Besides (1) degradation, which can lead to cell lysis, CWHs also participate to cell wall rearrangement and other key physiological functions, namely (2) turnover of cell wall material through their recycling to (3) biosynthesis, as well as (4) cell-to-cell communication (CTCC) since some released peptidoglycan fragments can act as signaling molecules or have (5) side effects on final protein subcellular localization, e.g., flagella, with consequences on motility, bacterial adhesion, biofilm formation, protein secretion, conjugation, virulence and/or immune response. CP, cytoplasm; CE, cell envelope; CW, cell wall; EM, extracellular milieu.

hydrolases genes have to be deleted to form chains of nonseparated cells (Vollmer et al., 2008b). CWAs have a prominent role in septum cleavage, in comparison with that of glycosidases and peptidases (Heidrich et al., 2001, 2002; Priyadarshini et al., 2006; Typas et al., 2012). The AmiA, AmiB, and AmiC CWAs play an important role in releasing daughter cells after cell division (Heidrich et al., 2001). AmiC appears to be the principal septum-cleaving enzyme in E. coli. Indeed, mutants inactivated in AmiC separate poorly, with about $30 \%$ of the population existing as chains of 3-6 unseparated cells, vs. $5-10 \%$ of the population in chains of 3-4 cells when only amiA is deleted, and no chaining effect upon deletion of $a m i B$ (Heidrich et al., 2001). In a mutant lacking AmiA, AmiB and AmiC CWAs, more than $90 \%$ of the cells exist as unseparated chains from 6 to 24 cells long (Priyadarshini et al., 2006). The cumulative effect of deleting all CWAs and CWPs as well as the Slt70 CWG is even more severe (Priyadarshini et al., 2006). The endopeptidases of the M23-LytM family are also implicated in the septation of E. coli cells (Typas et al., 2012). E. coli has four LytM paralogues, namely EnvC, NlpD, YgeR, and YebA, and their inactivation results in default in cell separation (Typas et al., 2012). In CW-monoderm bacteria, cleavage of the septum occurs simultaneously with cell division (Vollmer et al., 2008a). Several hydrolases contribute to this step, for example, an atl mutant of $S$. aureus and a lytB mutant of $S$. pneumoniae form clusters of non-separated cells (Vollmer et al., 2008a). Both hydrolases are localized at the sites of cell division.

In addition, CWHs can interact with each other and modulate their catalytic activity. In $E$. coli, the cell division proteins FtsN and FtsEX activate paralogs of LytM endopeptidases, namely EnvC and NlpD respectively, which further activate three amidases involved in the splitting of septum (Uehara et al., 2010; Typas et al., 2012); NlpD activates AmiC and EnVC activates AmiA and AmiB. In B. subtilis, FtsEX has also been shown to regulate the activity of $\mathrm{CwlO}$ (Dominguez-Cuevas et al., 2013; Meisner et al., 2013). Similarly, in S. pneumoniae, FtsEX activates the hydrolase PcsB (Sham et al., 2011). This hydrolase is essentially controlled by the sensor regulator $\mathrm{YycFG}$ ( $\mathrm{Ng}$ et al., 2003). The allosteric activation of E. coli amidase AmiB requires structural modification of the active site for substrate binding, and this mechanism seems to be conserved in amidases cleaving the septum (Yang et al., 2012). Similar activation by one or more 
protein(s) could also be applied to the E. coli D,D-endopeptidases Spr, YdhO, and YebA, which have low in vitro activity against PG (Singh et al., 2012). In the case of B. subtilis, the expression of the muramidase $\mathrm{YocH}$ and of the endopeptidases $\mathrm{CwlO}$, CwlF and LytE is controlled by the YycFG two-component system, which plays a key role in synchronizing CW metabolism and division (Bisicchia et al., 2007). The PG lipid II precursor or the process of its incorporation could be the signal sensed by YycFG (Bisicchia et al., 2007). In LPS-diderm bacteria, CWH activity is controlled by incorporation into multi enzyme complexes that span the periplasm, extending from inner membrane-anchored synthases to the hydrolases, some of which are associated with the outer membrane (Typas et al., 2012). Hydrolases in the complex may be localized at sites of PG synthesis, preventing them from hydrolysing PG elsewhere (Typas et al., 2012). In CW-monoderm bacteria, a direct interaction between PG synthases and hydrolases is generally not possible because they are physically separated; the synthases act in the inner face and the hydrolases on the outer layers (Carballido-Lopez et al., 2006). As already mentioned in B. subtilis, though, $\mathrm{CwlO}$ is activated by the membrane protein complex FtsEX, it has been suggested that its activity is restricted to the inner part of the PG layers (Dominguez-Cuevas et al., 2013). In this species, PG synthesis is controlled by the actin-like cytoplasmic protein MreBH, which forms filaments at the cytoplasmic membrane and directs the PG synthesis by co-localization of the synthases and the hydrolases (Carballido-Lopez et al., 2006). While colocalisation of synthases and hydrolases was proposed as model for the control of PG synthesis by the MreB cytoskeleton, later work in the field rather suggests that the localization of PG synthases and hydrolases is uncoupled (Dominguez-Cuevas et al., 2013; Meisner et al., 2013).

LTGs are involved in the assembly of large trans-envelope structures such as the secretion system of type II (T2SS), T3SS and T4SS, as well as surface organelles, including type 4 pili (T4P) and flagella (Koraimann, 2003; Zahrl et al., 2005; Scheurwater and Burrows, 2011; Herlihey and Clarke, 2017). They are required to enlarge gaps locally in the PG to allow the efficient assembly and anchoring of transport complexes in the cell envelope (Koraimann, 2003). For examples, VirB1 is involved in the assembly of the T4SS (Hoppner et al., 2005), FlgJ in the flagellum (Nambu et al., 1999; Hirano et al., 2001), and EtgA in the T3SS (Garcia-Gomez et al., 2011). While PilT is considered as involved in T2SS assembly, including T4P (Koraimann, 2003), its role remains to be ascertained. In $B$. subtilis, LytC and LytD CWHs have mutually compensatory roles in CW turnover and cell separation as well as motility (Horsburgh et al., 2003b). Besides cellular lysis, the AcmA CWG is involved in cell remodeling in L. lactis (Huard et al., 2004; Steen et al., 2005). In Salmonella Typhymurium, FlgJ (flagellar protein J) exhibits a GHF-73, whose CWG activity is essential for flagella assembly as it degrades the PG locally to enable the formation of the rod structure in the periplasmic space (Nambu et al., 1999).

\section{Recycling and Cell Lysis}

It has been established that a turnover of around $45 \%$ of the CW material occurs over one generation in bacteria (Goodell, 1985). In CW-monoderm bacteria, where PG generally accounts for more than $20 \%$ of the cell mass, vs. $2 \%$ in LPS-diderm bacteria, this would result in a significant loss of resources (Johnson et al., 2013). By providing the building blocks for $\mathrm{CW}$ biosynthesis, recycling is an energy saver mechanism for bacterial growth (Figure 7). Besides, when the bacterial cells are faced with a sudden loss of carbon, recycling of CW material would allow bacterial survival by completing a last round of cell division before growth arrest (Park and Uehara, 2008). While few data are available for CW-monoderm bacteria, E. coli has been widely used to investigate the processes of CW recycling (Park and Uehara, 2008). The major pathway involves the uptake of the anhydromuropeptides released in the periplasm from PG hydrolysis by the transporter AmpG specific for GlcNAc-1,6anhMurNAc and GlcNAc-1,6-anhMurNAc-peptides (Park and Uehara, 2008). These anhydromuropeptides are further degraded in the cytoplasm by the $\mathrm{N}$-acetylglucosaminidase NagZ, the anhMurNac-Lala amidase AmpD and the L,D-carboxypeptidase LdcA, and then join the PG synthesis pathway (Holtje et al., 1994; Templin et al., 1999; Cheng et al., 2000; Reith and Mayer, 2011; Johnson et al., 2013). While AmpD and AmpG are absent from CW-monoderm bacteria, CWGs of the lysozyme family play a more prominent role than $\mathrm{N}$ acetylglucosaminidase or LTGs (Reith and Mayer, 2011). Rather than anhydromuropeptides, lysozymes release MurNAccontaining muropeptides. In addition, hydrolysis of the stem peptides by amidases and peptidases plays a crucial role in PG degradation in CW-monoderm bacteria (Reith and Mayer, 2011). It has been shown that the $\mathrm{CW}$ of $S$. aureus must be pre-digested first with amidase before it becomes a good substrate for the glucosaminidase (Götz et al., 2014). Muropeptide cleavage occurs in the extracellular space of the CW compartment. Uptake of $\mathrm{CW}$ amino sugars will occur through the phosphotransferase system PTS permeases (NagP, MurP) and uptake of CW peptides through Mpp/Opp-like ABC transporters (Johnson et al., 2013). In S. aureus and B. subtilis, respectively, about 5 and $10 \%$ of the MurNac of the CW is recycled per generation (Borisova et al., 2016).

Autolysis can be induced by the inhibition of PG synthesis in growing cells (Vollmer et al., 2008b; Van Heijenoort, 2011). In this case, the autolysis in E. coli is not due to any specific induction of hydrolases but rather to an uncoupling between synthesis and degradation owing to an absence of control of the turnover CWHs (Van Heijenoort, 2011). Treatment of growing cells of E. coli with penicillin reduces the rate of PG synthesis and increases net lysis; a correlation has been established between induction of autolysis and inhibition of synthesis and degradation of PG by CWHs (Vollmer et al., 2008b). Autolysis of E. coli is low for non-growing cells and this can be attributed to PBP7 endopeptidase involvement in D-Ala-D-meso-A2pm crosslinkage, which contributes to structural changes of PG (Van Heijenoort, 2011). The activity of DdpX CWP exhibiting PM15 is considered as potentially lethal and owes to the hydrolysis of the D-Ala-D-Ala bond (Lessard et al., 1998). Overproduction of PBP5 CWP encoded by dacA and harboring a PS11 domain appeared to be lethal, causing $E$. coli cells to grow as spherically before lysing (Markiewicz et al., 1982). PBP5 regulates the availability of pentapeptide subunits for the formation of the 
cross-linkages by transpeptidation (Broome-Smith et al., 1988; Potluri et al., 2010; Van Heijenoort, 2011).

The myxobacteria, which are predatory bacteria, produce extracellular lytic agents including CWHs such as lysozyme and endo- $\beta-\mathrm{N}$-acetylglucosaminidase (Bourgerie et al., 1994). Similarly, Pseudomonas aeruginosa and other LPS-diderm bacteria deliver $\mathrm{NlpC} / \mathrm{P} 60$ type endopeptidases via T4SS into the periplasm of adjacent bacterial cells causing their lysis (Chou et al., 2012). The production of bacteriolytic exo-enzymes is also a property of many species of actinomycetes, in particular streptomycetes (Vollmer et al., 2008b). Lysis phenomena have been observed in the sporulation stage of myxobacteria and Bacillus, and will result in the release of nutrients (Vollmer et al., 2008b). In B. subtilis, the CwlB and CwlC CWAs with a NALAA3 domain are present in large amounts at the time of mother cell lysis (Smith and Foster, 1995). While single inactivation of $c w l B$ or $c w l C$ does not affect mother cell lysis, it was found to be blocked upon double gene knock-out (Nugroho et al., 1999). The CwlH CWA with a NALAA-2 domain was shown to be required for mother cell lysis and acts in a compensatory manner with CwlC (Nugroho et al., 1999; Yang et al., 2013). As CwlC, LytC is expressed only late in sporulation but is also involved in mother lysis (Smith and Foster, 1995).

Competent cells of $S$. pneumoniae are able to lyse noncompetent cells during co-cultivation, a phenomenon termed allolysis (Guiral et al., 2005). The mechanism involves the twopeptide bacteriocin $\mathrm{CibAB}$ and its immunity factor $\mathrm{CibC}$, as well as the LytA, LytC, and CbpD CWHs (Guiral et al., 2005). The bacteriocin activates the hydrolases, which disrupt the CW of the non-competent cells. Regulated bacterial death and lysis have been characterized in studies on the control of the lytic cycle during bacteriophage infection (Rice and Bayles, 2008). The mechanism controlling the bacteriophage-induced lysis involves a holin and a cognate CWH (Desvaux, 2012). In a first mechanism, upon activation of the holin, the membrane becomes leaky and allows the escape of the CWH to the PG and thus its degradation. The second mechanism involves bacteriophagesencoded CWH containing signal arrest release (SAR) domains (Rice and Bayles, 2008). This SAR-type hydrolase is transported in a Sec-dependant manner and anchors in the outer face of the membrane in an inactive form until the holin releases it.

CWHs must be highly regulated to prevent cell lysis. This regulation occurs at both the transcriptional and posttranslational levels. In B. subtilis, the transcription of the two hydrolases LytT and LytD is regulated by the sigma factor SigD, whereas LytE is regulated by SigA, SigH, and SigI (Serizawa et al., 2004). In S. aureus, perturbation of CW synthesis resulted in the modulation of the expression of the major CWH Atl by the two-component regulation system VraSR (vancomycin resistance-associated sensor/regulator) (Kuroda et al., 2003). In $S$. aureus, another two-component system LytSR controls the rate of autolysis by regulating the expression of $\operatorname{lrg} A B$ encoding an antiholin that interacts with holin to prevent cell lysis (Rice and Bayles, 2008). The interaction between the hydrolases and the CW is crucial for their activity, and their subcellular localization regulated at the post-translational level reflects their targeting mechanisms (Vollmer et al., 2008b).
Furthermore, most of these hydrolases have a binding domain for PG or other CW components that greatly enhances their enzymatic activity. Proteolytic processing of CWHs is common both for their activity and their stability in response to different environments. For example, the hydrolase Atl of S. aureus is produced as a proenzyme that undergoes proteolysis resulting in mature cell-surface and extracellular glucosamidase and amidase (Komatsuzawa et al., 1997). In LytC from S. pneumoniae, conformational changes in the GHF-25 domain play a key role in the control of the enzymatic activity to avoid self-lysis during bacterial growth and division (Perez-Dorado et al., 2010).

Finally, the activity of the hydrolases is regulated by their environment, such as the presence or not of other CW polymers, as illustrated by the teichoic acids that modify the activity of the amidase in B. subtilis or the growth at acidic $\mathrm{pH}$ that inhibits lysis (Vollmer et al., 2008b).

\section{Collateral Physiological Effects}

As reviewed above, the primary role of CWHs is the degradation of PG. The digestion can occur in a sparing manner for cleavage of the septum during cell division or spore maturation, enlargement of the sacculus, and assembly of supramolecular structures such as secretion systems, pili, or flagella (Vollmer et al., 2008b). The degradation can be more drastic in the case of the cell lysis, whether autolysis, allolysis, or exolysis (that is lysis of non-sibling prey cells). As a result of these CWH activities, several collateral effects of significance to bacterial physiology can further occur (Wyckoff et al., 2012). The expression of CWHs can affect the assembly of the supramolecular structure and indirectly modulate their affiliated function. For flagella, motility can be indirectly mitigated by FlgJ (Nambu et al., 1999), which could subsequently affect chemiotactism or surface colonization. By disturbing the assembly of pili, some CWHs could have side effects on bacterial aggregation, adhesion, biofilm formation, twitching motility or conjugation. For the secretion systems, some CWHs could incidentally modify the transport of proteins localized at the membrane, CW, periplasm, extracellular milieu or even injected into a host cell. Depending on the secreted proteins, a wide range of side effects could occur from substrate transport and cell adhesion to bacterial virulence.

In L. monocytogenes, CwhA (cell wall hydrolase A) was originally considered as a virulence factor per se, named Iap (invasion-associated protein) or P60 (protein of $60 \mathrm{KDa}$ ) at the time. Actually, it appeared to be primarily a $\mathrm{CWH}$ inducing septation default and consequently mislocalisation of key cell-surface virulence factors, namely the internalin InlA and the actin polymerisation factor ActA (Pilgrim et al., 2003; Desvaux and Hebraud, 2006). In addition, reduced secretion of both the CWHs CwhA and MurA via the SecA2 export pathway promotes extensive cell aggregation and sedimentation, as well as cell elongation inducing the formation of lowadherent filamentous biofilm (Machata et al., 2005; Renier et al., 2011, 2014). Regarding sessile development, the CWH activities can alter the global charge of the bacterial cell surface and/or modify the exposure of adhesin, which in turn modifies the bacterial aggregation/adhesion properties and/or 
biofilm formation abilities, as shown for AcmA from L. lactis (Mercier et al., 2002).

Besides recycling for $\mathrm{CW}$ biosynthesis, $\mathrm{PG}$ fragments released by the CWH activity could have messenger functions and act as signaling molecules (Boudreau et al., 2012) (Figure 7). In E. coli, muropeptides were shown to induce $\beta$-lactamase at the transcriptional level via the regulator AmpR (Jacobs et al., 1997). PG fragments could also initiate regrowth of dormant cells in the viable but nonculturable state (Keep et al., 2006). In the course of infection, these fragments can have proinflammatory activity and are recognized by PGRPs (peptidoglycan recognition proteins), which activate the immune response, especially the Toll or immune deficiency signal transduction pathways, or induce a proteolytic cascade generating antimicrobial compounds that induce phagocytosis or hydrolysis (Dziarski, 2003; Dziarski and Gupta, 2006; Markiewicz and Popowska, 2011). In Neisseria gonorrhoeae for instance, it is known for some times that PG fragments are cytotoxic to human ciliated Fallopian tube cells by causing their death and sloughing (Melly et al., 1984; Dillard, 2014). Besides, PG fragments from the neisserial CW influence the host innate immune response as they recognize and activate the NOD1 and NOD2 receptors (Mavrogiorgos et al., 2014; Knilans et al., 2017).

\section{CONCLUDING REMARKS}

While the biochemical composition of the bacterial CW is now well-known, its supramolecular organization and the interaction of the different constituents still require further studies. Biophysical investigations with state-of-the-art approaches have been performed on a handful of model bacteria, namely B. subtilis, S. aureus, or S. pneumoniae for CW-monoderm bacteria but quite restricted to $E$. coli for LPS-diderm bacteria (Vollmer et al., 2008a; Turner et al., 2010; Beaussart et al., 2014). Beyond the simplistic dichotomy of Gram-positive vs. Gram-negative bacteria, there is a need to encompass the full biodiversity of the bacterial kingdom considering the divergent molecular compositions and structural arrangements of the CW. As presented in this review, this can be more effectively embraced by considering the trichotomy of CW-monoderm, LPS-diderm and myco-diderm bacteria.

Rather than the designations of autolysin, endolysin and exolysin, which are confusing, ambiguous and quite often used misleadingly in the scientific literature, this review stresses the relevance of using instead the global term $\mathrm{CWH}$ (or $\mathrm{PGH}$ ) and the more specific designations of CWA, CWG, and CWP, for which conserved motifs and/or three-dimensional structures are clearly established. Besides, the combination of these latter terms, such as CWA-CWG or CWA-CWG-CWP, better reflect the modular organization of the numerous $\mathrm{CWH}$ exhibiting multiple catalytic sites. This comprehensive review of the diversity of conserved domains exhibiting $\mathrm{CWH}$ catalytic activity will help scientists in the field to describe the enzymes at hand. While the association of different catalytic properties generally results in synergistic effects, the CW binding motifs that can be found along the monopolypeptide, generally improve the efficiency of the enzymatic activity (Shoseyov et al., 2006). While some CWHs attracted a lot of interest very early, e.g. the lysostaphin (Schindler and Schuhardt, 1964), this review also stresses numerous domains that have yet to be fully characterized and that only a handful of investigations have been dedicated to the biochemical, catalytic, molecular, structural and/or physiological characterization of enzymes with multiple catalytic sites and/or CW binding domains (Figures 3-6). In other words, the synergistic and processive effects of such combinations of domains have yet to be elucidated. Of note and besides LTG domains, some CWHs can exhibit additional catalytic domains unrelated to $\mathrm{CW}$ degradation or $\mathrm{CW}$ biosynthesis but this aspect has not been really explored yet. Interestingly, lysozyme activity was recently uncovered in the Ruminococcus champellensis cellulosome (Morais et al., 2016) and several dockerin-containing CWHs enable to associate to the cohesion domains of a scaffoldin were further reported (Bensoussan et al., 2017). Beyond the cellulosome dedicated to the degradation of plant materials (Shoham et al., 1999; Desvaux, 2005; Smith et al., 2017), a new concept could emerge, that is an extracellular multi-enzymes complex dedicated to bacterial cell lysis, i.e. the lyticome. Clearly, our knowledge of the full diversity of CWHs is still incomplete and new conserved domains will most likely be uncovered in the years to come. Yet more complex are the regulation and modulation of expression as well as activity of CWHs. These secreted enzymes are not only regulated at the transcriptional level but also at different translational and post-translational levels, including translocational and conformational levels, which are the first regulatory levels. A complete understanding of their interactions with CW components and of enzymatic interplay is most certainly the next frontier for breakthroughs in the field, without counting on the many side effects of these enzymes on the bacterial ecophysiology, a topic of much current interest (Wyckoff et al., 2012).

\section{AUTHOR CONTRIBUTIONS}

$\mathrm{AV}$ and MD wrote the first overall draft of the manuscript and drew the original pictures. SL, RT, MP, and CP wrote sections of the manuscript. MD, SL, and RT contributed to conceptualize the overarching aims. MD had management as well as coordination responsibility for the execution of the work. $\mathrm{MD}$ and $\mathrm{CP}$ contributed to the acquisition of the financial supports and resources leading to this publication. All authors contributed to the critical revision of the manuscript, read and approved the submitted version.

\section{ACKNOWLEDGMENTS}

This work was supported in part by INRA (Institut National de la Recherche Agronomique), the DéESSe project from the Région Auvergne and FEDER (Fonds Européen de Développement Régional), the Polish National Center of Science $\left(\mathrm{n}^{\circ} 2013 / 09 / \mathrm{B} / \mathrm{NZ6} / 00710\right)$, and the Campus France PHC (Programme Hubert Curien) France-Poland POLONIUM (n²8298ZE). AV was a post-doctoral research fellow supported by a Bourse Innovation Transfert de Technologie. We are very grateful to David Marsh (djmarsh@wanadoo.fr) for correcting the European English of the manuscript. 


\section{REFERENCES}

Abaev, I., Foster-Frey, J., Korobova, O., Shishkova, N., Kiseleva, N., Kopylov, P., et al. (2013). Staphylococcal Phage 2638A endolysin is lytic for Staphylococcus aureus and harbors an inter-lytic-domain secondary translational start site. Appl. Microbiol. Biotechnol. 97, 3449-3456. doi: 10.1007/s00253-012-4252-4

Albrecht, T., Raue, S., Rosenstein, R., Nieselt, K., and Götz, F. (2012). Phylogeny of the staphylococcal major autolysin and its use in genus and species typing. J. Bacteriol. 194, 2630-2636. doi: 10.1128/JB.06609-11

Alcorlo, M., Martinez-Caballero, S., Molina, R., and Hermoso, J. A. (2017). Carbohydrate recognition and lysis by bacterial peptidoglycan hydrolases. Curr. Opin. Struct. Biol. 44, 87-100. doi: 10.1016/j.sbi.2017.01.001

Alderwick, L. J., Harrison, J., Lloyd, G. S., and Birch, H. L. (2015). The mycobacterial cell wall-peptidoglycan and arabinogalactan. Cold Spring Harb. Perspect. Med. 5:a021113. doi: 10.1101/cshperspect.a021113

Al-Riyami, B., Ustok, F. I., Stott, K., Chirgadze, D. Y., and Christie, G. (2016). The crystal structure of Clostridium perfringens SleM, a muramidase involved in cortical hydrolysis during spore germination. Proteins 84, 1681-1689. doi: $10.1002 /$ prot.25112

Amir, A., Babaeipour, F., Mcintosh, D. B., Nelson, D. R., and Jun, S. (2014). Bending forces plastically deform growing bacterial cell walls. Proc. Natl. Acad. Sci. USA. 111, 5778-5783. doi: 10.1073/pnas.1317497111

Anantharaman, V., and Aravind, L. (2003). Evolutionary history, structural features and biochemical diversity of the NlpC/P60 superfamily of enzymes. Genome Biol. 4:R11. doi: 10.1186/gb-2003-4-5-p3

Arbeloa, A., Hugonnet, J. E., Sentilhes, A. C., Josseaume, N., Dubost, L., Monsempes, C., et al. (2004). Synthesis of mosaic peptidoglycan cross-bridges by hybrid peptidoglycan assembly pathways in Gram-positive bacteria. J. Biol. Chem. 279, 41546-41556. doi: 10.1074/jbc.M407149200

Atrih, A., Bacher, G., Allmaier, G., Williamson, M. P., and Foster, S. J. (1999). Analysis of peptidoglycan structure from vegetative cells of Bacillus subtilis 168 and role of PBP 5 in peptidoglycan maturation. J. Bacteriol. 181, 3956-3966.

Bacik, J. P., Whitworth, G. E., Stubbs, K. A., Vocadlo, D. J., and Mark, B. L. (2012). Active site plasticity within the glycoside hydrolase NagZ underlies a dynamic mechanism of substrate distortion. Chem. Biol. 19, 1471-1482. doi: 10.1016/j.chembiol.2012.09.016

Bai, X. H., Chen, H. J., Jiang, Y. L., Wen, Z., Huang, Y., Cheng, W., et al. (2014). Structure of pneumococcal peptidoglycan hydrolase LytB reveals insights into the bacterial cell wall remodeling and pathogenesis. J. Biol. Chem. 289, 23403-23416. doi: 10.1074/jbc.M114.579714

Barreteau, H., Kovac, A., Boniface, A., Sova, M., Gobec, S., and Blanot, D. (2008). Cytoplasmic steps of peptidoglycan biosynthesis. FEMS Microbiol. Rev. 32, 168-207. doi: 10.1111/j.1574-6976.2008.00104.x

Bateman, A., and Bycroft, M. (2000). The structure of a LysM domain from Escherichia coli membrane-bound lytic murein transglycosylase D (MltD). J. Mol. Biol. 299, 1113-1119. doi: 10.1006/jmbi.2000.3778

Bateman, A., and Rawlings, N. D. (2003). The CHAP domain: a large family of amidases including GSP amidase and peptidoglycan hydrolases. Trends Biochem. Sci. 28, 234-237. doi: 10.1016/S0968-0004(03)00061-6

Beaussart, A., Pechoux, C., Trieu-Cuot, P., Hols, P., Mistou, M. Y., and Dufrene, Y. F. (2014). Molecular mapping of the cell wall polysaccharides of the human pathogen Streptococcus agalactiae. Nanoscale 6, 14820-14827. doi: $10.1039 / C 4 N R 05280 \mathrm{C}$

Becker, S. C., Dong, S., Baker, J. R., Foster-Frey, J., Pritchard, D. G., and Donovan, D. M. (2009). LysK CHAP endopeptidase domain is required for lysis of live staphylococcal cells. FEMS Microbiol. Lett. 294, 52-60. doi: 10.1111/j.1574-6968.2009.01541.x

Becker, S. C., Swift, S., Korobova, O., Schischkova, N., Kopylov, P., Donovan, D. M., et al. (2015). Lytic activity of the staphylolytic Twort phage endolysin CHAP domain is enhanced by the SH3b cell wall binding domain. FEMS Microbiol. Lett. 362, 1-8. doi: 10.1093/femsle/fnu019

Bensoussan, L., Morais, S., Dassa, B., Friedman, N., Henrissat, B., Lombard, V., et al. (2017). Broad phylogeny and functionality of cellulosomal components in the bovine rumen microbiome. Environ. Microbiol. 19, 185-197. doi: 10.1111/1462-2920.13561

Bianchet, M. A., Pan, Y. H., Basta, L. A. B., Saavedra, H., Lloyd, E. P., Kumar, P., et al. (2017). Structural insight into the inactivation of Mycobacterium tuberculosis non-classical transpeptidase LdtMt2 by biapenem and tebipenem. BMC Biochem. 18:8. doi: 10.1186/s12858-017-0082-4

Bisicchia, P., Noone, D., Lioliou, E., Howell, A., Quigley, S., Jensen, T., et al. (2007). The essential YycFG two-component system controls cell wall metabolism in Bacillus subtilis. Mol. Microbiol. 65, 180-200. doi: 10.1111/j.1365-2958.2007.05782.x

Blackburn, N. T., and Clarke, A. J. (2001). Identification of four families of peptidoglycan lytic transglycosylases. J. Mol. Evol. 52, 78-84. doi: $10.1007 / \mathrm{s} 002390010136$

Boneca, I. G., Huang, Z. H., Gage, D. A., and Tomasz, A. (2000). Characterization of Staphylococcus aureus cell wall glycan strands, evidence for a new $\beta$-N-acetylglucosaminidase activity. J. Biol. Chem. 275, 9910-9918. doi: $10.1074 /$ jbc.275.14.9910

Borisova, M., Gaupp, R., Duckworth, A., Schneider, A., Dalügge, D., Mühleck, M., et al. (2016). Peptidoglycan recycling in Gram-Positive bacteria is crucial for survival in stationary phase. mBio 7:e00923-16. doi: 10.1128/mBio. 00923-16

Bosma, T., Kanninga, R., Neef, J., Audouy, S.a.L., Van Roosmalen, M. L., Steen, A., et al. (2006). Novel surface display system for proteins on nongenetically modified Gram-positive bacteria. Appl. Environ. Microbiol. 72, 880-889. doi: 10.1128/AEM.72.1.880-889.2006

Boudreau, M. A., Fisher, J. F., and Mobashery, S. (2012). Messenger functions of the bacterial cell wall-derived muropeptides. Biochemistry 51, 2974-2990. doi: $10.1021 / \mathrm{bi3} 300174 \mathrm{x}$

Bouhss, A., Trunkfield, A. E., Bugg, T. D., and Mengin-Lecreulx, D. (2008). The biosynthesis of peptidoglycan lipid-linked intermediates. FEMS Microbiol. Rev. 32, 208-233. doi: 10.1111/j.1574-6976.2007.00089.x

Bourgerie, S., Karamanos, Y., Grard, T., and Julien, R. (1994). Purification and characterization of an endo-N-acetyl- $\beta$ - $\mathrm{D}$-glucosaminidase from the culture medium of Stigmatella aurantiaca DW4. J. Bacteriol. 176, 6170-6174. doi: $10.1128 / \mathrm{jb}$.176.20.6170-6174.1994

Bourhis, L. L., and Werts, C. (2007). Role of Nods in bacterial infection. Microbes Infect. 9, 629-636. doi: 10.1016/j.micinf.2007.01.014

Broendum, S. S., Buckle, A. M., and Mcgowan, S. (2018). Catalytic diversity and cell wall binding repeats in the phage-encoded endolysins. Mol. Microbiol. 110, 879-896. doi: 10.1111/mmi.14134

Broome-Smith, J. K., Ioannidis, I., Edelman, A., and Spratt, B. G. (1988). Nucleotide sequences of the penicillin-binding protein 5 and 6 genes of Escherichia coli. Nucleic Acids Res. 16:1617. doi: 10.1093/nar/16.4.1617

Bublitz, M., Polle, L., Holland, C., Heinz, D. W., Nimtz, M., and Schubert, W. D. (2009). Structural basis for autoinhibition and activation of Auto, a virulenceassociated peptidoglycan hydrolase of Listeria monocytogenes. Mol. Microbiol. 71, 1509-1522. doi: 10.1111/j.1365-2958.2009.06619.x

Buist, G., Steen, A., Kok, J., and Kuipers, O. P. (2008). LysM, a widely distributed protein motif for binding to (peptido)glycans. Mol. Microbiol. 68, 838-847. doi: 10.1111/j.1365-2958.2008.06211.x

Bussiere, D. E., Pratt, S. D., Katz, L., Severin, J. M., Holzman, T., and Park, C. H. (1998). The structure of VanX reveals a novel amino-dipeptidase involved in mediating transposon-based vancomycin resistance. Mol. Cell 2, 75-84. doi: 10.1016/S1097-2765(00)80115-X

Buttner, F. M., Zoll, S., Nega, M., Gotz, F., and Stehle, T. (2014). Structurefunction analysis of Staphylococcus aureus amidase reveals the determinants of peptidoglycan recognition and cleavage. J. Biol. Chem. 289, 11083-11094. doi: 10.1074/jbc.M114.557306

Callewaert, L., and Michiels, C. W. (2010). Lysozymes in the animal kingdom. J. Biosci. 35, 127-160. doi: 10.1007/s12038-010-0015-5

Callewaert, L., Van Herreweghe, J. M., Vanderkelen, L., Leysen, S., Voet, A., and Michiels, C. W. (2012). Guards of the great wall: bacterial lysozyme inhibitors. Trends Microbiol. 20, 501-510. doi: 10.1016/j.tim.2012.06.005

Carballido-Lopez, R., Formstone, A., Li, Y., Ehrlich, S. D., Noirot, P., and Errington, J. (2006). Actin homolog MreBH governs cell morphogenesis by localization of the cell wall hydrolase LytE. Dev. Cell 11, 399-409. doi: 10.1016/j.devcel.2006.07.017

Carrasco-Lopez, C., Rojas-Altuve, A., Zhang, W., Hesek, D., Lee, M., Barbe, S., et al. (2011). Crystal structures of bacterial peptidoglycan amidase AmpD and an unprecedented activation mechanism. J. Biol. Chem. 286, 31714-31722. doi: $10.1074 / j b c . M 111.264366$ 
Cheng, Q., Li, H., Merdek, K., and Park, J. T. (2000). Molecular characterization of the $\beta$-N-acetylglucosaminidase of Escherichia coli and its role in cell wall recycling. J. Bacteriol. 182, 4836-4840. doi: 10.1128/JB.182.17.4836-4840.2000

Chipman, D. M., Grisaro, V., and Sharon, N. (1967). The binding of oligosaccharides containing $\mathrm{N}$-acetylglucosamine and $\mathrm{N}$-acetylmuramic acid to lysozyme. The specificity of binding subsites. J. Biol. Chem. 242, 4388-4394.

Chou, S., Bui, N. K., Russell, A. B., Lexa, K. W., Gardiner, T. E., Leroux, M., et al. (2012). Structure of a peptidoglycan amidase effector targeted to Gramnegative bacteria by the Type VI secretion system. Cell Rep. 1, 656-664. doi: 10.1016/j.celrep.2012.05.016

D’angelo, T., Oshone, R., Abebe-Akele, F., Simpson, S., Morris, K., Thomas, W. K., et al. (2016). Permanent draft genome sequence for Frankia sp. strain EI5c, a single-spore isolate of a nitrogen-fixing Actinobacterium, isolated from the root nodules of Elaeagnus angustifolia. Genome Announc. 4:e00660-16. doi: 10.1128/genomeA.00660-16

D'aquino, J. A., and Ringe, D. (2003). Determinants of the Src Homology Domain 3-Like Fold. J. Bacteriol. 185, 4081-4086. doi: 10.1128/JB.185.14.4081-4086.2003

Davies, C., White, S. W., and Nicholas, R. A. (2001). Crystal structure of a deacylation-defective mutant of penicillin-binding protein 5 at $2.3-\mathrm{A}$ resolution. J. Biol. Chem. 276, 616-623. doi: 10.1074/jbc.M004471200

Desvaux, M. (2005). The cellulosome of Clostridium cellulolyticum. Enz Microbiol Technol 37, 373-385. doi: 10.1016/j.enzmictec.2004.04.025

Desvaux, M. (2012). Contribution of holins to protein trafficking: secretion, leakage or lysis? Trends Microbiol. 20, 259-261. doi: 10.1016/j.tim.2012.03.008

Desvaux, M., Candela, T., and Serror, P. (2018). Surfaceome and proteosurfaceome in parietal monoderm bacteria: focus on protein cell-surface display. Front. Microbiol. 9:100. doi: 10.3389/fmicb.2018.00100

Desvaux, M., Dumas, E., Chafsey, I., and Hebraud, M. (2006). Protein cell surface display in Gram-positive bacteria: from single protein to macromolecular protein structure. FEMS Microbiol Lett. 256, 1-15. doi: $10.1111 / j .1574-6968.2006 .00122 . x$

Desvaux, M., and Hebraud, M. (2006). The protein secretion systems in Listeria: inside out bacterial virulence. FEMS Microbiol. Rev. 30, 774-805. doi: 10.1111/j.1574-6976.2006.00035.x

Dillard, J. P. (2014). "Peptidoglycan metabolism and fragment production," in Pathogenic Neisseria: Genomics, Molecular Biology and Disease Intervention, eds. J. K. Davies, C. M. Kahler (Norfolk: Caister Academic Press), 97-114.

Dmitriev, B. A., Toukach, F. V., Holst, O., Rietschel, E. T., and Ehlers, S. (2004). Tertiary structure of Staphylococcus aureus cell wall murein. J. Bacteriol. 186, 7141-7148. doi: 10.1128/JB.186.21.7141-7148.2004

Doehn, J. M., Fischer, K., Reppe, K., Gutbier, B., Tschernig, T., Hocke, A. C., et al. (2013). Delivery of the endolysin Cpl-1 by inhalation rescues mice with fatal pneumococcal pneumonia. J. Antimicrob. Chemother. 68, 2111-2117. doi: $10.1093 /$ jac/dkt131

Dominguez-Cuevas, P., Porcelli, I., Daniel, R. A., and Errington, J. (2013). Differentiated roles for MreB-actin isologues and autolytic enzymes in Bacillus subtilis morphogenesis. Mol. Microbiol. 89, 1084-1098. doi: $10.1111 / \mathrm{mmi} .12335$

Dramsi, S., Magnet, S., Davison, S., and Arthur, M. (2008). Covalent attachment of proteins to peptidoglycan. FEMS Microbiol. Rev. 32, 307-320. doi: $10.1111 / j .1574-6976.2008 .00102 . x$

Dziarski, R. (2003). Recognition of bacterial peptidoglycan by the innate immune system. Cell. Mol. Life Sci. 60, 1793-1804. doi: 10.1007/s00018-003-3019-6

Dziarski, R., and Gupta, D. (2006). The peptidoglycan recognition proteins (PGRPs). Genome Biol. 7:232. doi: 10.1186/gb-2006-7-8-232

Egan, A. J., Biboy, J., Van't Veer, I., Breukink, E., and Vollmer, W. (2015). Activities and regulation of peptidoglycan synthases. Philos. Trans. R. Soc. Lond. 370:20150031. doi: 10.1098/rstb.2015.0031

Fenton, M., Ross, P., Mcauliffe, O., O'mahony, J., and Coffey, A. (2010). Recombinant bacteriophage lysins as antibacterials. Bioeng. Bugs 1, 9-16. doi: 10.4161/bbug.1.1.9818

Finn, R. D., Coggill, P., Eberhardt, R. Y., Eddy, S. R., Mistry, J., Mitchell, A. L., et al. (2016). The Pfam protein families database: towards a more sustainable future. Nucleic Acids Res. 44, D279-285. doi: 10.1093/nar/gkv1344

Firczuk, M., and Bochtler, M. (2007). Folds and activities of peptidoglycan amidases. FEMS Microbiol. Rev. 31, 676-691. doi: $10.1111 /$ j.1574-6976.2007.00084.x
Firczuk, M., Mucha, A., and Bochtler, M. (2005). Crystal structures of active LytM. J. Mol. Biol. 354, 578-590. doi: 10.1016/j.jmb.2005.09.082

Fleming, A. (1929). On the antibacterial action of cultures of a penicillium, with special reference to their use in the isolation of B. influenzae. Bull World Health Organ. 79, 780-790.

Fonze, E., Vermeire, M., Nguyen-Disteche, M., Brasseur, R., and Charlier, P. (1999). The crystal structure of a penicilloyl-serine transferase of intermediate penicillin sensitivity. The DD-transpeptidase of Streptomyces K15. J. Biol. Chem. 274, 21853-21860. doi: 10.1074/jbc.274.31.21853

Foster, S. J. (1993). Analysis of Bacillus subtilis 168 prophageassociated lytic enzymes; identification and characterization of CWLA-related prophage proteins. J. Gen. Microbiol. 139, 3177-3184. doi: 10.1099/00221287-139-12-3177

Frankel, M. B., and Schneewind, O. (2012). Determinants of murein hydrolase targeting to cross-wall of Staphylococcus aureus peptidoglycan. J. Biol. Chem. 287, 10460-10471. doi: 10.1074/jbc.M111.336404

Garcia, P., Garcia, E., Ronda, C., Lopez, R., and Tomasz, A. (1983). A phageassociated murein hydrolase in Streptococcus pneumoniae infected with bacteriophage Dp-1. J. Gen. Microbiol. 129, 489-497.

Garcia-Gomez, E., Espinosa, N., De La Mora, J., Dreyfus, G., and GonzalezPedrajo, B. (2011). The muramidase EtgA from enteropathogenic Escherichia coli is required for efficient Type III secretion. Microbiology 157, 1145-1160. doi: 10.1099/mic.0.045617-0

Glauner, B., Holtje, J. V., and Schwarz, U. (1988). The composition of the murein of Escherichia coli. J. Biol. Chem. 263, 10088-10095.

Gokulan, K., Khare, S., Cerniglia, C. E., Foley, S. L., and Varughese, K. I. (2018). Structure and inhibitor specificity of L,D-transpeptidase (LdtMt2) from Mycobacterium tuberculosis and antibiotic resistance: calcium binding promotes dimer formation. AAPS J. 20:44. doi: 10.1208/s12248-0180193-x

Goodell, E. W. (1985). Recycling of murein by Escherichia coli. J. Bacteriol. $163,305-10$.

Götz, F., Heilmann, C., and Stehle, T. (2014). Functional and structural analysis of the major amidase (Atl) in Staphylococcus. Int. J. Med. Microbiol. 304, 156-163. doi: 10.1016/j.ijmm.2013.11.006

Grabowska, M., Jagielska, E., Czapinska, H., Bochtler, M., and Sabala, I. (2015). High resolution structure of an M23 peptidase with a substrate analogue. Sci. Rep. 5:14833. doi: 10.1038/srep14833

Gu, J., Feng, Y., Feng, X., Sun, C., Lei, L., Ding, W., et al. (2014). Structural and biochemical characterization reveals LysGH15 as an unprecedented "EF-hand-like" calcium-binding phage lysin. PLoS Pathog. 10:e1004109. doi: 10.1371/journal.ppat.1004109

Guiral, S., Mitchell, T. J., Martin, B., and Claverys, J. P. (2005). Competenceprogrammed predation of noncompetent cells in the human pathogen Streptococcus pneumoniae: genetic requirements. Proc. Natl. Acad. Sci. U.S.A. 102, 8710-8715. doi: 10.1073/pnas.0500879102

Harz, H., Burgdorf, K., and Holtje, J. V. (1990). Isolation and separation of the glycan strands from murein of Escherichia coli by reversed-phase high-performance liquid chromatography. Anal. Biochem. 190, 120-128. doi: 10.1016/0003-2697(90)90144-X

Hashimoto, W., Ochiai, A., Momma, K., Itoh, T., Mikami, B., Maruyama, Y., et al. (2009). Crystal structure of the glycosidase family 73 peptidoglycan hydrolase FlgJ. Biochem. Biophys. Res. Commun. 381, 16-21. doi: 10.1016/j.bbrc.2009.01.186

Havarstein, L. S., Martin, B., Johnsborg, O., Granadel, C., and Claverys, J. P. (2006). New insights into the pneumococcal fratricide: relationship to clumping and identification of a novel immunity factor. Mol. Microbiol. 59, 1297-1307. doi: 10.1111/j.1365-2958.2005.05021.x

Heidrich, C., Templin, M. F., Ursinus, A., Merdanovic, M., Berger, J., Schwarz, $\mathrm{H}$., et al. (2001). Involvement of $\mathrm{N}$-acetylmuramyl-L-alanine amidases in cell separation and antibiotic-induced autolysis of Escherichia coli. Mol. Microbiol. 41, 167-178. doi: 10.1046/j.1365-2958.2001.02499.x

Heidrich, C., Ursinus, A., Berger, J., Schwarz, H., and Holtje, J. V. (2002). Effects of multiple deletions of murein hydrolases on viability, septum cleavage, and sensitivity to large toxic molecules in Escherichia coli. J. Bacteriol. 184, 6093-6099. doi: 10.1128/JB.184.22.6093-6099.2002

Heilmann, C., Hussain, M., Peters, G., and Gotz, F. (1997). Evidence for autolysin-mediated primary attachment of Staphylococcus 
epidermidis to a polystyrene surface. Mol. Microbiol. 24, 1013-1024. doi: 10.1046/j.1365-2958.1997.4101774.x

Herlihey, F. A., and Clarke, A. J. (2017). Controlling autolysis during flagella insertion in gram-negative bacteria. Adv. Exp. Med. Biol. 925, 41-56. doi: 10.1007/5584_2016_52

Hirano, T., Minamino, T., and Macnab, R. M. (2001). The role in flagellar rod assembly of the N-terminal domain of Salmonella FlgJ, a flagellum-specific muramidase. J. Mol. Biol. 312, 359-369. doi: 10.1006/jmbi.2001.4963

Holtje, J. V. (1995). From growth to autolysis: the murein hydrolases in Escherichia coli. Arch. Microbiol. 164, 243-254. doi: 10.1007/BF02529958

Holtje, J. V. (1996). A hypothetical holoenzyme involved in the replication of the murein sacculus of Escherichia coli. Microbiology 142, 1911-1918. doi: 10.1099/13500872-142-8-1911

Holtje, J. V. (1998). Growth of the stress-bearing and shape-maintaining murein sacculus of Escherichia coli. Microbiol. Mol. Biol. Rev. 62, 181-203.

Holtje, J. V., Kopp, U., Ursinus, A., and Wiedemann, B. (1994). The negative regulator of $\beta$-lactamase induction $A m p D$ is a $\mathrm{N}$-acetylanhydromuramyl-L-alanine amidase. FEMS Microbiol. Lett. 122, 159-164. doi: 10.1111/j.1574-6968.1994.tb07159.x

Höltje, J. V., Mirelman, D., Sharon, N., and Schwarz, U. (1975). Novel type of murein transglycosylase in Escherichia coli. J. Bacteriol. 124, 1067-1076.

Hoppner, C., Carle, A., Sivanesan, D., Hoeppner, S., and Baron, C. (2005). The putative lytic transglycosylase VirB1 from Brucella suis interacts with the Type IV secretion system core components VirB8, VirB9 and VirB11. Microbiology 151, 3469-3482. doi: 10.1099/mic.0.28326-0

Horgan, M., O’flynn, G., Garry, J., Cooney, J., Coffey, A., Fitzgerald, G. F., et al. (2009). Phage lysin LysK can be truncated to its CHAP domain and retain lytic activity against live antibiotic-resistant staphylococci. Appl. Environ. Microbiol. 75, 872-874. doi: 10.1128/AEM.01831-08

Horsburgh, G. J., Atrih, A., and Foster, S. J. (2003a). Characterization of LytH, a differentiation-associated peptidoglycan hydrolase of Bacillus subtilis involved in endospore cortex maturation. J. Bacteriol. 185, 3813-3820. doi: 10.1128/JB.185.13.3813-3820.2003

Horsburgh, G. J., Atrih, A., Williamson, M. P., and Foster, S. J. (2003b). LytG of Bacillus subtilis is a novel peptidoglycan hydrolase: the major active glucosaminidase. Biochemistry 42, 257-264. doi: 10.1021/bi020498c

Huard, C., Miranda, G., Redko, Y., Wessner, F., Foster, S. J., and ChapotChartier, M. P. (2004). Analysis of the peptidoglycan hydrolase complement of Lactococcus lactis: identification of a third Nacetylglucosaminidase, AcmC. Appl. Environ. Microbiol. 70, 3493-3499. doi: 10.1128/AEM.70.6.3493-3499.2004

Huard, C., Miranda, G., Wessner, F., Bolotin, A., Hansen, J., Foster, S. J., et al. (2003). Characterization of AcmB, an $\mathrm{N}$-acetylglucosaminidase autolysin from Lactococcus lactis. Microbiology 149, 695-705. doi: 10.1099/mic.0.25875-0

Humann, J., and Lenz, L. L. (2009). Bacterial peptidoglycan degrading enzymes and their impact on host muropeptide detection. J. Innate Immun. 1, 88-97. doi: 10.1159/000181181

Inagaki, N., Iguchi, A., Yokoyama, T., Yokoi, K. J., Ono, Y., Yamakawa, A., et al. (2009). Molecular properties of the glucosaminidase AcmA from Lactococcus lactis MG1363: mutational and biochemical analyses. Gene 447, 61-71. doi: 10.1016/j.gene.2009.08.004

Jackson, M. (2014). The mycobacterial cell envelope-lipids. Cold Spring Harb. Perspect. Med. 4:a021105. doi: 10.1101/cshperspect.a021105

Jacobs, C., Frere, J. M., and Normark, S. (1997). Cytosolic intermediates for cell wall biosynthesis and degradation control inducible $\beta$-lactam resistance in Gram-negative bacteria. Cell 88, 823-832. doi: 10.1016/S0092-8674(00)81928-5

Johnson, J. W., Fisher, J. F., and Mobashery, S. (2013). Bacterial cell-wall recycling. Ann. N. Y. Acad. Sci. 1277:54-75. doi: 10.1111/j.1749-6632.2012.06813.x

Jolles, P. (1996). From the discovery of lysozyme to the characterization of several lysozyme families. EXS. 1996;75:3-5. doi: 10.1007/978-3-0348-9225-4_1

Kajimura, J., Fujiwara, T., Yamada, S., Suzawa, Y., Nishida, T., Oyamada, Y., et al. (2005). Identification and molecular characterization of an N-acetylmuramylL-alanine amidase Sle1 involved in cell separation of Staphylococcus aureus. Mol. Microbiol. 58, 1087-1101. doi: 10.1111/j.1365-2958.2005.04881.x

Karamanos, Y. (1997). Endo-N-acetyl- $\beta$-D-glucosaminidases and their potential substrates: structure/function relationships. Res. Microbiol. 148, 661-671. doi: 10.1016/S0923-2508(99)80065-5
Keary, R., Sanz-Gaitero, M., Van Raaij, M. J., O’mahony, J., Fenton, M., Mcauliffe, O., et al. (2016). Characterization of a Bacteriophage-Derived Murein Peptidase for Elimination of Antibiotic-Resistant Staphylococcus aureus. Curr. Protein Pept. Sci. 17, 183-190. doi: 10.2174/1389203716666151102105515

Keck, W., Van Leeuwen, A. M., Huber, M., and Goodell, E. W. (1990). Cloning and characterization of mepA, the structural gene of the penicillin-insensitive murein endopeptidase from Escherichia coli. Mol. Microbiol. 4, 209-219. doi: 10.1111/j.1365-2958.1990.tb00588.x

Keep, N. H., Ward, J. M., Cohen-Gonsaud, M., and Henderson, B. (2006). Wake up! Peptidoglycan lysis and bacterial non-growth states. Trends Microbiol 14, 271-276. doi: 10.1016/j.tim.2006.04.003

Kim, H. S., Im, H. N., An, D. R., Yoon, J. Y., Jang, J. Y., Mobashery, S., et al. (2015). The cell shape-determining Csd6 protein from Helicobacter pylori constitutes a new family of L,D-carboxypeptidase. J. Biol. Chem. 290, 25103-25117. doi: $10.1074 /$ jbc.M115.658781

Kim, H. S., Kim, J., Im, H. N., Yoon, J. Y., An, D. R., Yoon, H. J., et al. (2013). Structural basis for the inhibition of Mycobacterium tuberculosis L,D-transpeptidase by meropenem, a drug effective against extensively drug-resistant strains. Acta Crystallogr. D Biol. Crystallogr. 69, 420-431. doi: 10.1107/S0907444912048998

Knilans, K. J., Hackett, K. T., Anderson, J. E., Weng, C., Dillard, J. P., and Duncan, J. A. (2017). Neisseria gonorrhoeae lytic transglycosylases LtgA and LtgD reduce host innate immune signaling through TLR2 and NOD2. ACS Infect Dis 3, 624-633. doi: 10.1021/acsinfecdis.6b00088

Koch, A. L., and Doyle, R. J. (1985). Inside-to-outside growth and turnover of the wall of gram-positive rods. J. Theor. Biol. 117, 137-157. doi: 10.1016/S0022-5193(85)80169-7

Komatsuzawa, H., Sugai, M., Nakashima, S., Yamada, S., Matsumoto, A., Oshida, T., et al. (1997). Subcellular localization of the major autolysin, ATL and its processed proteins in Staphylococcus aureus. Microbiol. Immunol. 41, 469-479. doi: 10.1111/j.1348-0421.1997.tb01880.x

Koraimann, G. (2003). Lytic transglycosylases in macromolecular transport systems of Gram-negative bacteria. Cell. Mol. Life Sci. 60, 2371-2388. doi: 10.1007/s00018-003-3056-1

Kumar, P., Kaushik, A., Lloyd, E. P., Li, S. G., Mattoo, R., Ammerman, N. C., et al. (2017). Non-classical transpeptidases yield insight into new antibacterials. Nat. Chem. Biol. 13, 54-61. doi: 10.1038/nchembio.2237

Kuroda, M., Kuroda, H., Oshima, T., Takeuchi, F., Mori, H., and Hiramatsu, K. (2003). Two-component system VraSR positively modulates the regulation of cell-wall biosynthesis pathway in Staphylococcus aureus. Mol. Microbiol. 49, 807-821. doi: 10.1046/j.1365-2958.2003.03599.x

Lawson, P. A., Citron, D. M., Tyrrell, K. L., and Finegold, S. M. (2016). Reclassification of Clostridium difficile as Clostridioides difficile (Hall and O’Toole 1935) Prevot 1938. Anaerobe 40, 95-99. doi: 10.1016/j.anaerobe.2016.06.008

Lee, M., Artola-Recolons, C., Carrasco-Lopez, C., Martinez-Caballero, S., Hesek, D., Spink, E., et al. (2013). Cell-wall remodeling by the zinc-protease AmpDh3 from Pseudomonas aeruginosa. J. Am. Chem. Soc. 135, 12604-12607. doi: $10.1021 /$ ja407445x

Lessard, I. A., Pratt, S. D., Mccafferty, D. G., Bussiere, D. E., Hutchins, C., Wanner, B. L., et al. (1998). Homologs of the vancomycin resistance D-Ala-D-Ala dipeptidase VanX in Streptomyces toyocaensis, Escherichia coli and Synechocystis: attributes of catalytic efficiency, stereoselectivity and regulation with implications for function. Chem. Biol. 5, 489-504. doi: 10.1016/S1074-5521(98)90005-9

Letunic, I., and Bork, P. (2018). 20 years of the SMART protein domain annotation resource. Nucleic Acids Res. 46, D493-D496. doi: 10.1093/nar/gkx922

Li, W. J., Li, D. F., Hu, Y. L., Zhang, X. E., Bi, L. J., and Wang, D. C. (2013). Crystal structure of L,D-transpeptidase LdtMt2 in complex with meropenem reveals the mechanism of carbapenem against Mycobacterium tuberculosis. Cell Res. 23, 728-731. doi: $10.1038 / \mathrm{cr} .2013 .53$

Li, Y., Jin, K., Setlow, B., Setlow, P., and Hao, B. (2012). Crystal structure of the catalytic domain of the Bacillus cereus SleB protein, important in cortex peptidoglycan degradation during spore germination. J. Bacteriol. 194, 4537-4545. doi: 10.1128/JB.00877-12

Liepinsh, E., Genereux, C., Dehareng, D., Joris, B., and Otting, G. (2003). NMR structure of Citrobacter freundii AmpD, comparison with bacteriophage T7 
lysozyme and homology with PGRP domains. J. Mol. Biol. 327, 833-842. doi: 10.1016/S0022-2836(03)00185-2

Litzinger, S., Fischer, S., Polzer, P., Diederichs, K., Welte, W., and Mayer, C. (2010). Structural and kinetic analysis of Bacillus subtilis $\mathrm{N}$-acetylglucosaminidase reveals a unique Asp-His dyad mechanism. J. Biol. Chem. 285, 35675-35684. doi: 10.1074/jbc.M110.131037

Llull, D., Lopez, R., and Garcia, E. (2006). Skl, a novel choline-binding Nacetylmuramoyl-L-alanine amidase of Streptococcus mitis SK137 containing a CHAP domain. FEBS Lett. 580, 1959-1964. doi: 10.1016/j.febslet.2006. 02.060

Lopez, R., Garcia, E., and Concepcion, R. (1981). Bacteriophages of Streptococcus pneumoniae. Rev. Infect. Dis. 3, 212-223. doi: 10.1093/clinids/3.2.212

Lu, J. Z., Fujiwara, T., Komatsuzawa, H., Sugai, M., and Sakon, J. (2006). Cell wall-targeting domain of glycylglycine endopeptidase distinguishes among peptidoglycan cross-bridges. J. Biol. Chem. 281, 549-558. doi: 10.1074/jbc.M509691200

Ma, Y., Bai, G., Cui, Y., Zhao, J., Yuan, Z., and Liu, X. (2017). Crystal Structure of Murein-Tripeptide Amidase MpaA from Escherichia coli $\mathrm{O} 157$ at 2.6 A Resolution. Protein Pept. Lett. 24, 181-187. doi: 10.2174/0929866523666161128153128

Machata, S., Hain, T., Rohde, M., and Chakraborty, T. (2005). Simultaneous deficiency of both MurA and p60 proteins generates a rough phenotype in Listeria monocytogenes. J. Bacteriol. 187, 8385-8394. doi: 10.1128/JB.187.24.8385-8394.2005

Macheboeuf, P., Contreras-Martel, C., Job, V., Dideberg, O., and Dessen, A. (2006). Penicillin binding proteins: key players in bacterial cell cycle and drug resistance processes. FEMS Microbiol. Rev. 30, 673-691. doi: 10.1111/j.1574-6976.2006.00024.x

Magnet, S., Dubost, L., Marie, A., Arthur, M., and Gutmann, L. (2008). Identification of the L,D-transpeptidases for peptidoglycan cross-linking in Escherichia coli. J. Bacteriol. 190, 4782-4785. doi: 10.1128/JB.00025-08

Marchler-Bauer, A., Bo, Y., Han, L., He, J., Lanczycki, C. J., Lu, S., et al. (2017). CDD/SPARCLE: functional classification of proteins via subfamily domain architectures. Nucleic Acids Res. 45, D200-D203. doi: 10.1093/nar/gkw1129

Marcyjaniak, M., Odintsov, S. G., Sabala, I., and Bochtler, M. (2004). Peptidoglycan amidase MepA is a LAS metallopeptidase. J. Biol. Chem. 279, 43982-43989. doi: 10.1074/jbc.M406735200

Markiewicz, Z., Broome-Smith, J. K., Schwarz, U., and Spratt, B. G. (1982). Spherical Escherichia coli due to elevated levels of D-alanine carboxypeptidase. Nature 297, 702-704. doi: 10.1038/297702a0

Markiewicz, Z., and Popowska, M. (2011). An update on some structural aspects of the mighty miniwall. Pol. J. Microbiol. 60, 181-186.

Martinez-Caballero, S., Lee, M., Artola-Recolons, C., Carrasco-Lopez, C., Hesek, D., Spink, E., et al. (2013). Reaction products and the X-ray structure of AmpDh2, a virulence determinant of Pseudomonas aeruginosa. J. Am. Chem. Soc. 135, 10318-10321. doi: 10.1021/ja405464b

Maruyama, Y., Ochiai, A., Itoh, T., Mikami, B., Hashimoto, W., and Murata, K. (2010). Mutational studies of the peptidoglycan hydrolase FlgJ of Sphingomonas sp. strain A1. J. Basic Microbiol. 50, 311-317. doi: 10.1002/jobm.200900249

Mavrogiorgos, N., Mekasha, S., Yang, Y., Kelliher, M. A., and Ingalls, R. R. (2014). Activation of NOD receptors by Neisseria gonorrhoeae modulates the innate immune response. Innate Immun. 20, 377-389. doi: $10.1177 / 1753425913493453$

Mckenzie, H. A. (1996). alpha-Lactalbumins and lysozymes. EXS 75, 365-409. doi: 10.1007/978-3-0348-9225-4_19

Meisner, J., Montero Llopis, P., Sham, L. T., Garner, E., Bernhardt, T. G., and Rudner, D. Z. (2013). FtsEX is required for CwlO peptidoglycan hydrolase activity during cell wall elongation in Bacillus subtilis. Mol. Microbiol. 89, 1069-1083. doi: $10.1111 / \mathrm{mmi} .12330$

Melly, M. A., Mcgee, Z. A., and Rosenthal, R. S. (1984). Ability of monomeric peptidoglycan fragments from Neisseria gonorrhoeae to damage human fallopian-tube mucosa. J. Infect. Dis. 149, 378-386. doi: 10.1093/infdis/149.3.378

Mercier, C., Durrieu, C., Briandet, R., Domakova, E., Tremblay, J., Buist, G., et al. (2002). Positive role of peptidoglycan breaks in lactococcal biofilm formation. Mol. Microbiol. 46, 235-243. doi: 10.1046/j.1365-2958.2002.03160.x

Meziane-Cherif, D., Stogios, P. J., Evdokimova, E., Savchenko, A., and Courvalin, P. (2014). Structural basis for the evolution of vancomycin resistance D,D-peptidases. Proc. Natl. Acad. Sci. U.S.A. 111, 5872-5877. doi: 10.1073/pnas.1402259111

Mitchell, A. L., Attwood, T. K., Babbitt, P. C., Blum, M., Bork, P., Bridge, A., et al. (2019). InterPro in 2019: improving coverage, classification and access to protein sequence annotations. Nucleic Acids Res. 47, D351-D360. doi: $10.1093 /$ nar/gky1100

Mooers, B. H., and Matthews, B. W. (2006). Extension to 2268 atoms of direct methods in the ab initio determination of the unknown structure of bacteriophage P22 lysozyme. Acta Crystallogr. D Biol. Crystallogr. 62, 165-176. doi: 10.1107/S0907444905037212

Morais, S., Cockburn, D. W., Ben-David, Y., Koropatkin, N. M., Martens, E. C., Duncan, S. H., et al. (2016). Lysozyme activity of the Ruminococcus champanellensis cellulosome. Environ. Microbiol. 18, 5112-5122. doi: 10.1111/1462-2920.13501

Nagl, S. B. (2003). "Function prediction from protein sequence," in Bioinformatics: Genes, Proteins and Computers, eds. C. Orengo, D. Jones, J. Thornton (Oxford: BIOS scientific Publishers), 64-78.

Nambu, T., Minamino, T., Macnab, R. M., and Kutsukake, K. (1999). Peptidoglycan-hydrolyzing activity of the FlgJ protein, essential for flagellar rod formation in Salmonella Typhimurium. J. Bacteriol. 181, 1555-1561.

Nelson, D. E., and Young, K. D. (2001). Contributions of PBP5 and DD-carboxypeptidase penicillin binding proteins to maintenance of cell shape in Escherichia coli. J. Bacteriol. 183, 3055-3064. doi: 10.1128/JB.183.10.3055-3064.2001

Neuhaus, F. C., and Baddiley, J. (2003). A continuum of anionic charge: structures and functions of d-alanyl-teichoic acids in Gram-positive bacteria. Microbiol. Mol. Biol. Rev. 67, 686-723. doi: 10.1128/MMBR.67.4.686-723.2003

Ng, W. L., Robertson, G. T., Kazmierczak, K. M., Zhao, J., Gilmour, R., and Winkler, M. E. (2003). Constitutive expression of PcsB suppresses the requirement for the essential $\mathrm{VicR}(\mathrm{YycF})$ response regulator in Streptococcus pneumoniae R6. Mol. Microbiol. 50, 1647-1663. doi: 10.1046/j.1365-2958.2003.03806.x

Niederweis, M., Danilchanka, O., Huff, J., Hoffmann, C., and Engelhardt, H. (2010). Mycobacterial outer membranes: in search of proteins. Trends Microbiol. 18, 109-116. doi: 10.1016/j.tim.2009.12.005

Nugroho, F. A., Yamamoto, H., Kobayashi, Y., and Sekiguchi, J. (1999). Characterization of a new sigma-K-dependent peptidoglycan hydrolase gene that plays a role in Bacillus subtilis mother cell lysis. J. Bacteriol. 181, 6230-6237.

Odintsov, S. G., Sabala, I., Marcyjaniak, M., and Bochtler, M. (2004). Latent LytM at 1.3A resolution. J. Mol. Biol. 335, 775-785. doi: 10.1016/j.jmb.2003. 11.009

O'flaherty, S., Coffey, A., Meaney, W., Fitzgerald, G. F., and Ross, R. P. (2005). The recombinant phage lysin LysK has a broad spectrum of lytic activity against clinically relevant staphylococci, including methicillin-resistant Staphylococcus aureus. J. Bacteriol. 187, 7161-7164. doi: 10.1128/JB.187.20.7161-7164.2005

Ohnishi, R., Ishikawa, S., and Sekiguchi, J. (1999). Peptidoglycan hydrolase LytF plays a role in cell separation with CwlF during vegetative growth of Bacillus subtilis. J. Bacteriol. 181, 3178-3184.

Oshida, T., Sugai, M., Komatsuzawa, H., Hong, Y. M., Suginaka, H., and Tomasz, A. (1995). A Staphylococcus aureus autolysin that has an N-acetylmuramoyl$\mathrm{L}$-alanine amidase domain and an endo- $\beta-\mathrm{N}$-acetylglucosaminidase domain: cloning, sequence analysis, and characterization. Proc. Natl. Acad. Sci. 92, 285-289. doi: 10.1073/pnas.92.1.285

Ozdemir, I., Blumer-Schuette, S. E., Kelly, R. M. (2012). S-layer homology domain proteins Csac_0678 and Csac_2722 are implicated in plant polysaccharide deconstruction by the extremely thermophilic bacterium Caldicellulosiruptor saccharolyticus. Appl. Environ. Microbiol. 78, 768-777. doi: 10.1128/AEM.07031-11

Park, J. T., and Uehara, T. (2008). How bacteria consume their own exoskeletons (turnover and recycling of cell wall peptidoglycan). Microbiol. Mol. Biol. Rev. 72, 211-227. doi: 10.1128/MMBR.00027-07

Pei, J., and Grishin, N. V. (2005). COG3926 and COG5526: a tale of two new lysozyme-like protein families. Protein Sci. 14, 2574-2581. doi: 10.1110/ps.051656805

Pennartz, A., Généreux, C., Parquet, C., Mengin-Lecreulx, D., and Joris, B. (2009). Substrate-induced inactivation of the Escherichia coli AmiD $\mathrm{N}$-acetylmuramoyl-1-alanine amidase highlights a new strategy to inhibit 
this class of enzyme. Antimicrob. Agents Chemother. 53, 2991-2997. doi: 10.1128/AAC.01520-07

Perez-Dorado, I., Campillo, N. E., Monterroso, B., Hesek, D., Lee, M., Paez, J. A., et al. (2007). Elucidation of the molecular recognition of bacterial cell wall by modular pneumococcal phage endolysin CPL-1. J. Biol. Chem. 282, 24990-24999. doi: 10.1074/jbc.M704317200

Perez-Dorado, I., Gonzalez, A., Morales, M., Sanles, R., Striker, W., Vollmer, W., et al. (2010). Insights into pneumococcal fratricide from the crystal structures of the modular killing factor LytC. Nat. Struct. Mol. Biol. 17, 576-581. doi: $10.1038 / \mathrm{nsmb} .1817$

Pilgrim, S., Kolb-Maurer, A., Gentschev, I., Goebel, W., and Kuhn, M. (2003). Deletion of the gene encoding p60 in Listeria monocytogenes leads to abnormal cell division and loss of actin-based motility. Infect. Immun. 71, 3473-3484. doi: 10.1128/IAI.71.6.3473-3484.2003

Popowska, M., and Markiewicz, Z. (2004). Classes and functions of Listeria monocytogenes surface proteins. Pol. J. Microbiol. 53, 75-88.

Potluri, L., Karczmarek, A., Verheul, J., Piette, A., Wilkin, J. M., Werth, N., et al. (2010). Septal and lateral wall localization of PBP5, the major D,D-carboxypeptidase of Escherichia coli, requires substrate recognition and membrane attachment. Mol. Microbiol. 77, 300-323. doi: 10.1111/j.1365-2958.2010.07205.x

Priyadarshini, R., Popham, D. L., and Young, K. D. (2006). Daughter cell separation by penicillin-binding proteins and peptidoglycan amidases in Escherichia coli. J. Bacteriol. 188, 5345-5355. doi: 10.1128/JB.00476-06

Reith, J., and Mayer, C. (2011). Peptidoglycan turnover and recycling in Gram-positive bacteria. Appl. Microbiol. Biotechnol. 92, 1-11. doi: 10.1007/s00253-011-3486-x

Renier, S., Chagnot, C., Deschamps, J., Caccia, N., Szlavik, J., Joyce, S. A., et al. (2014). Inactivation of the SecA2 protein export pathway in Listeria monocytogenes promotes cell aggregation, impacts biofilm architecture and induces biofilm formation in environmental condition. Environ. Microbiol. 16, 1176-1192. doi: 10.1111/1462-2920.12257

Renier, S., Hebraud, M., and Desvaux, M. (2011). Molecular biology of surface colonization by Listeria monocytogenes: an additional facet of an opportunistic Gram-positive foodborne pathogen. Environ. Microbiol. 13, 835-850. doi: 10.1111/j.1462-2920.2010.02378.x

Rhazi, N., Charlier, P., Dehareng, D., Engher, D., Vermeire, M., Frere, J. M., et al. (2003). Catalytic mechanism of the Streptomyces K15 DDtranspeptidase/penicillin-binding protein probed by site-directed mutagenesis and structural analysis. Biochemistry 42, 2895-2906. doi: 10.1021/bi027256x

Rice, K. C., and Bayles, K. W. (2008). Molecular control of bacterial death and lysis. Microbiol. Mol. Biol. Rev. 72, 85-109. doi: 10.1128/MMBR. 00030-07

Rigden, D. J., Jedrzejas, M. J., and Galperin, M. Y. (2003). Amidase domains from bacterial and phage autolysins define a family of gammaD,L-glutamate-specific amidohydrolases. Trends Biochem. Sci. 28, 230-234. doi: 10.1016/S0968-0004(03)00062-8

Rocaboy, M., Herman, R., Sauvage, E., Remaut, H., Moonens, K., Terrak, M., et al. (2013). The crystal structure of the cell division amidase AmiC reveals the fold of the AMIN domain, a new peptidoglycan binding domain. Mol. Microbiol. 90, 267-277. doi: 10.1111/mmi.12361

Rossi, P., Aramini, J. M., Xiao, R., Chen, C. X., Nwosu, C., Owens, L. A., et al. (2009). Structural elucidation of the Cys-His-Glu-Asn proteolytic relay in the secreted CHAP domain enzyme from the human pathogen Staphylococcus saprophyticus. Proteins 74, 515-519. doi: 10.1002/prot.22267

Sabala, I., Jagielska, E., Bardelang, P. T., Czapinska, H., Dahms, S. O., Sharpe, J. A., et al. (2014). Crystal structure of the antimicrobial peptidase lysostaphin from Staphylococcus simulans. FEBS J. 281, 4112-4122. doi: 10.1111/febs.12929

Sabala, I., Jonsson, I.-M., Tarkowski, A., and Bochtler, M. (2012). Antistaphylococcal activities of lysostaphin and LytM catalytic domain. BMC Microbiol. 12:97. doi: 10.1186/1471-2180-12-97

Sanders, A. N., and Pavelka, M. S. (2013). Phenotypic analysis of Eschericia coli mutants lacking L,D-transpeptidases. Microbiology 159, 1842-1852. doi: 10.1099/mic.0.069211-0

Sanz-Gaitero, M., Keary, R., Garcia-Doval, C., Coffey, A., and Van Raaij, M. J. (2014). Crystal structure of the lytic $\mathrm{CHAP}(\mathrm{K})$ domain of the endolysin LysK from Staphylococcus aureus bacteriophage K. Virol. J. 11:133. doi: $10.1186 / 1743-422 \mathrm{X}-11-133$
Sauvage, E., Kerff, F., Terrak, M., Ayala, J. A., and Charlier, P. (2008). The penicillin-binding proteins: structure and role in peptidoglycan biosynthesis. FEMS Microbiol. Rev. 32, 234-258. doi: 10.1111/j.1574-6976.2008.00105.x

Scheffers, D. J., and Pinho, M. G. (2005). Bacterial cell wall synthesis: new insights from localization studies. Microbiol. Mol. Biol. Rev. 69, 585-607. doi: 10.1128/MMBR.69.4.585-607.2005

Scheurwater, E., Reid, C. W., and Clarke, A. J. (2008). Lytic transglycosylases: bacterial space-making autolysins. Int. J. Biochem. Cell Biol. 40, 586-591. doi: 10.1016/j.biocel.2007.03.018

Scheurwater, E. M., and Burrows, L. L. (2011). Maintaining network security: how macromolecular structures cross the peptidoglycan layer. FEMS Microbiol. Lett. 318, 1-9. doi: 10.1111/j.1574-6968.2011.02228.x

Schindler, C. A., and Schuhardt, V. T. (1964). Lysostaphin: a new bacteriolytic agent for the staphylococcus Proc. Natl. Acad. Sci. U.S.A. 51, 414-421. doi: 10.1073/pnas.51.3.414

Schleifer, K. H., and Kandler, O. (1972). Peptidoglycan types of bacterial cell walls and their taxonomic implications. Bacteriol. Rev. 36, 407-477.

Schmelcher, M., Donovan, D. M., and Loessner, M. J. (2012). Bacteriophage endolysins as novel antimicrobials. Future Microbiol. 7, 1147-1171. doi: $10.2217 /$ fmb.12.97

Schneewind, O., Fowler, A., and Faull, K. F. (1995). Structure of the cell wall anchor of surface proteins in Staphylococcus aureus. Science 268, 103-106. doi: 10.1126/science.7701329

Serizawa, M., Yamamoto, H., Yamaguchi, H., Fujita, Y., Kobayashi, K., Ogasawara, N., et al. (2004). Systematic analysis of SigD-regulated genes in Bacillus subtilis by DNA microarray and Northern blotting analyses. Gene 329, 125-136. doi: 10.1016/j.gene.2003.12.024

Sham, L.-T., Barendt, S. M., Kopecky, K. E., and Winkler, M. E. (2011). Essential PcsB putative peptidoglycan hydrolase interacts with the essential FtsX(Spn) cell division protein in Streptococcus pneumoniae D39. Proc. Natl. Acad. Sci. U.S.A. 108, E1061-E1069. doi: 10.1073/pnas.1108323108

Shao, X., Ni, H., Lu, T., Jiang, M., Li, H., Huang, X., et al. (2012). An improved system for the surface immobilisation of proteins on Bacillus thuringiensis vegetative cells and spores through a new spore cortex-lytic enzyme anchor. N. Biotechnol. 29, 302-310. doi: 10.1016/j.nbt.2011.09.003

Shockman, G. D., Daneo-Moore, L., Kariyama, R., and Massidda, O. (1996). Bacterial walls, peptidoglycan hydrolases, autolysins, and autolysis. Microbial. Drug Resistance 2, 95-98. doi: 10.1089/mdr.1996.2.95

Shoham, Y., Lamed, R., and Bayer, E. A. (1999). The cellulosome concept as an efficient microbial strategy for the degradation of insoluble polysaccharides. Trends Microbiol. 7, 275-281. doi: 10.1016/S0966-842X(99)01533-4

Shoseyov, O., Shani, Z., and Levy, I. (2006). Carbohydrate binding modules: biochemical properties and novel applications. Microbiol. Mol. Biol. Rev. 70, 283-295. doi: 10.1128/MMBR.00028-05

Silhavy, T. J., Kahne, D., and Walker, S. (2010). The bacterial cell envelope. Cold Spring Harb. Perspect. Biol. 2:a000414. doi: 10.1101/cshperspect.a000414

Singh, S. K., Saisree, L., Amrutha, R. N., and Reddy, M. (2012). Three redundant murein endopeptidases catalyse an essential cleavage step in peptidoglycan synthesis of Escherichia coli K12. Mol. Microbiol. 86, 1036-1051. doi: $10.1111 / \mathrm{mmi} .12058$

Smith, S. P., Bayer, E. A., and Czjzek, M. (2017). Continually emerging mechanistic complexity of the multi-enzyme cellulosome complex. Curr. Opin. Struct. Biol. 44, 151-160. doi: 10.1016/j.sbi.2017.03.009

Smith, T. J., Blackman, S. A., and Foster, S. J. (2000). Autolysins of Bacillus subtilis: multiple enzymes with multiple functions. Microbiology 146, 249-262. doi: 10.1099/00221287-146-2-249

Smith, T. J., and Foster, S. J. (1995). Characterization of the involvement of two compensatory autolysins in mother cell lysis during sporulation of Bacillus subtilis 168. J. Bacteriol. 177, 3855-3862. doi: 10.1128/jb.177.13.3855-3862.1995

Sobhanifar, S., King, D. T., and Strynadka, N. C. (2013). Fortifying the wall: synthesis, regulation and degradation of bacterial peptidoglycan. Curr. Opin. Struct. Biol. 23, 695-703. doi: 10.1016/j.sbi.2013.07.008

Steen, A., Buist, G., Horsburgh, G. J., Venema, G., Kuipers, O. P., Foster, S. J., et al. (2005). AcmA of Lactococcus lactis is an $\mathrm{N}$-acetylglucosaminidase with an optimal number of LysM domains for proper functioning. FEBS J. 272, 2854-2868. doi: 10.1111/j.1742-4658.2005.04706.x

Stubbs, K. A., Balcewich, M., Mark, B. L., and Vocadlo, D. J. (2007). Small molecule inhibitors of a glycoside hydrolase attenuate inducible 
AmpC-mediated $\beta$-lactam resistance. J. Biol. Chem. 282, 21382-21391. doi: 10.1074/jbc.M700084200

Sugai, M., Fujiwara, T., Akiyama, T., Ohara, M., Komatsuzawa, H., Inoue, S., et al. (1997). Purification and molecular characterization of glycylglycine endopeptidase produced by Staphylococcus capitis EPK1. J. Bacteriol. 179, 1193-1202. doi: 10.1128/jb.179.4.1193-1202.1997

Szweda, P., Schielmann, M., Kotlowski, R., Gorczyca, G., Zalewska, M., and Milewski, S. (2012). Peptidoglycan hydrolases-potential weapons against Staphylococcus aureus. Appl. Microbiol. Biotechnol. 96, 1157-1174. doi: $10.1007 / \mathrm{s} 00253-012-4484-3$

Templin, M. F., Ursinus, A., and Höltje, J.-V. (1999). A defect in cell wall recycling triggers autolysis during the stationary growth phase of Escherichia coli. EMBO J. 18, 4108-4117. doi: $10.1093 /$ emboj/18.15.4108

Torti, S. V., and Park, J. T. (1976). Lipoprotein of Gram-negative bacteria is essential for growth and division. Nature 263, 323-326. doi: 10.1038/263323a0

Turner, R. D., Ratcliffe, E. C., Wheeler, R., Golestanian, R., Hobbs, J. K., and Foster, S. J. (2010). Peptidoglycan architecture can specify division planes in Staphylococcus aureus. Nat. Commun. 1:26. doi: 10.1038/ncomms1025

Turner, R. D., Vollmer, W., and Foster, S. J. (2014). Different walls for rods and balls: the diversity of peptidoglycan. Mol. Microbiol. 91, 862-874. doi: $10.1111 / \mathrm{mmi} .12513$

Typas, A., Banzhaf, M., Gross, C. A., and Vollmer, W. (2012). From the regulation of peptidoglycan synthesis to bacterial growth and morphology. Nat. Rev. Microbiol. 10, 123-136. doi: 10.1038/nrmicro2677

Uehara, T., and Park, J. T. (2003). Identification of MpaA, an amidase in Escherichia coli that hydrolyzes the $\gamma$-d-Glutamyl-mesoDiaminopimelate bond in murein peptides. J. Bacteriol. 185, 679-682. doi: $10.1128 / J B .185 .2 .679-682.2003$

Uehara, T., Parzych, K. R., Dinh, T., and Bernhardt, T. G. (2010). Daughter cell separation is controlled by cytokinetic ring-activated cell wall hydrolysis. EMBO J. 29, 1412-1422. doi: 10.1038/emboj.2010.36

Van Heijenoort, J. (2001). Formation of the glycan chains in the synthesis of bacterial peptidoglycan. Glycobiology 11, 25R-36R. doi: $10.1093 / \mathrm{glycob} / 11.3 .25 \mathrm{R}$

Van Heijenoort, J. (2011). Peptidoglycan Hydrolases of Escherichia coli. Microbiol. Mol. Biol. Rev. 75, 636-663. doi: 10.1128/MMBR.00022-11

Varghese, J. N., Hrmova, M., and Fincher, G. B. (1999). Three-dimensional structure of a barley $\beta$-D-glucan exohydrolase, a family 3 glycosyl hydrolase. Structure 7, 179-190. doi: 10.1016/S0969-2126(99)80024-0

Visweswaran, G. R., Steen, A., Leenhouts, K., Szeliga, M., Ruban, B., HesselingMeinders, A., et al. (2013). AcmD, a homolog of the major autolysin AcmA of Lactococcus lactis, binds to the cell wall and contributes to cell separation and autolysis. PLoS ONE 8:e72167. doi: 10.1371/journal.pone.00 72167

Visweswaran, G. R. R., Leenhouts, K., Van Roosmalen, M., Kok, J., and Buist, G. (2014). Exploiting the peptidoglycan-binding motif, LysM, for medical and industrial applications. Appl. Microbiol. Biotechnol. 98, 4331-4345. doi: $10.1007 / \mathrm{s} 00253-014-5633-7$

Vollmer, W. (2012). Bacterial growth does require peptidoglycan hydrolases. Mol. Microbiol. 86, 1031-1035. doi: 10.1111/mmi.12059

Vollmer, W., Blanot, D., and De Pedro, M. A. (2008a). Peptidoglycan structure and architecture. FEMS Microbiol. Rev. 32, 149-167. doi: 10.1111/j.1574-6976.2007.00094.x

Vollmer, W., and Holtje, J. V. (2004). The architecture of the murein (peptidoglycan) in gram-negative bacteria: vertical scaffold or horizontal layer(s)? J. Bacteriol. 186, 5978-5987. doi: 10.1128/JB.186.18.5978-5987.2004

Vollmer, W., Joris, B., Charlier, P., and Foster, S. (2008b). Bacterial peptidoglycan (murein) hydrolases. FEMS Microbiol. Rev. 32, 259-286. doi: 10.1111/j.1574-6976.2007.00099.x

Votsch, W., and Templin, M. F. (2000). Characterization of a $\beta-\mathrm{N}-$ acetylglucosaminidase of Escherichia coli and elucidation of its role in muropeptide recycling and $\beta$-lactamase induction. J. Biol. Chem. 275, 39032-39038. doi: 10.1074/jbc.M004797200

Weidel, W., and Pelzer, H. (1964). Bagshaped macromolecules-a new outlook on bacterial cell walls. Adv. Enzymol. Relat. Subj. Biochem. J. 26, 193-232. doi: 10.1002/9780470122716.ch5
Wright, G. D., Molinas, C., Arthur, M., Courvalin, P., and Walsh, C. T. (1992). Characterization of VanY, a DD-carboxypeptidase from vancomycin-resistant Enterococcus faecium BM4147. Antimicrob. Agents Chemother. 36, 1514-1518. doi: 10.1128/AAC.36.7.1514

Wyckoff, T. J., Taylor, J. A., and Salama, N. R. (2012). Beyond growth: novel functions for bacterial cell wall hydrolases. Trends Microbiol. 20, 540-547. doi: $10.1016 /$ j.tim.2012.08.003

Xu, Q., Chiu, H. J., Farr, C. L., Jaroszewski, L., Knuth, M. W., Miller, M. D., et al. (2014). Structures of a bifunctional cell wall hydrolase CwlT containing a novel bacterial lysozyme and an NlpC/P60 DL-endopeptidase. J. Mol. Biol. 426, 169-184. doi: 10.1016/j.jmb.2013.09.011

Xu, Q., Mengin-Lecreulx, D., Liu, X. W., Patin, D., Farr, C. L., Grant, J. C., et al. (2015). Insights into substrate specificity of NlpC/P60 cell wall hydrolases containing bacterial SH3 domains. MBio 6, e02327-e02314. doi: $10.1128 / \mathrm{mBio} .02327-14$

Yamada, S., Sugai, M., Komatsuzawa, H., Nakashima, S., Oshida, T., Matsumoto, A., et al. (1996). An autolysin ring associated with cell separation of Staphylococcus aureus. J. Bacteriol. 178, 1565-1571. doi: $10.1128 / \mathrm{jb}$.178.6.1565-1571.1996

Yamamoto, E., Muramatsu, H., and Nagai, K. (2014). Vulgatibacter incomptus gen. nov., sp. nov. and Labilithrix luteola gen. nov., sp. nov., two myxobacteria isolated from soil in Yakushima Island, and the description of Vulgatibacteraceae fam. nov., Labilitrichaceae fam. nov. and Anaeromyxobacteraceae fam. nov. Int. J. Syst. Evol. Microbiol. 64, 3360-3368. doi: 10.1099/ijs.0.063198-0

Yang, D. C., Tan, K., Joachimiak, A., and Bernhardt, T. G. (2012). A conformational switch controls cell wall-remodelling enzymes required for bacterial cell division. Mol. Microbiol. 85, 768-781. doi: 10.1111/j.1365-2958.2012.08138.x

Yang, J., Peng, Q., Chen, Z., Deng, C., Shu, C., Zhang, J., et al. (2013). Transcriptional regulation and characteristics of a novel $\mathrm{N}$-acetylmuramoylL-alanine amidase gene involved in Bacillus thuringiensis mother cell lysis. J. Bacteriol. 195, 2887-2897. doi: 10.1128/JB.00112-13

Young, R. (1992). Bacteriophage lysis: mechanism and regulation. Microbiol. Rev. $56,430-481$.

Yu, M., Yang, J., and Guo, M. (2016). Is the LysM domain of Listeria monocytogenes p60 protein suitable for engineering a protein with high peptidoglycan binding affinity? Bioengineered 7, 406-410. doi: 10.1080/21655979.2016.1200772

Yutin, N., and Galperin, M. Y. (2013). A genomic update on clostridial phylogeny: Gram-negative spore formers and other misplaced clostridia. Environ. Microbiol. 15, 2631-2641. doi: 10.1111/1462-2920.12173

Zahrl, D., Wagner, M., Bischof, K., Bayer, M., Zavecz, B., Beranek, A., et al. (2005). Peptidoglycan degradation by specialized lytic transglycosylases associated with Type III and Type IV secretion systems. Microbiology 151, 3455-3467. doi: 10.1099/mic.0.28141-0

Zoll, S., Schlag, M., Shkumatov, A. V., Rautenberg, M., Svergun, D. I., Gotz, F., et al. (2012). Ligand-binding properties and conformational dynamics of autolysin repeat domains in staphylococcal cell wall recognition. J. Bacteriol. 194, 3789-3802. doi: 10.1128/JB.00331-12

Zou, Y., and Hou, C. (2010). Systematic analysis of an amidase domain CHAP in 12 Staphylococcus aureus genomes and 44 staphylococcal phage genomes. Comput. Biol. Chem. 34, 251-257. doi: 10.1016/j.compbiolchem.2010.07.001

Conflict of Interest Statement: CP is permanent employee of BioFilm Control and declare his company provided support in the form of salary.

The remaining authors declare that the research was conducted in the absence of any commercial or financial relationships that could be construed as a potential conflict of interest.

Copyright (c) 2019 Vermassen, Leroy, Talon, Provot, Popowska and Desvaux. This is an open-access article distributed under the terms of the Creative Commons Attribution License (CC BY). The use, distribution or reproduction in other forums is permitted, provided the original author (s) and the copyright owner(s) are credited and that the original publication in this journal is cited, in accordance with accepted academic practice. No use, distribution or reproduction is permitted which does not comply with these terms. 